\title{
WestVirginiaUniversity
}

THE RESEARCH REPOSITORY @ WVU

Graduate Theses, Dissertations, and Problem Reports

2002

\section{Ant colony heuristics for the dynamic facility layout problem}

Jin Shang

West Virginia University

Follow this and additional works at: https://researchrepository.wvu.edu/etd

\section{Recommended Citation}

Shang, Jin, "Ant colony heuristics for the dynamic facility layout problem" (2002). Graduate Theses,

Dissertations, and Problem Reports. 1260.

https://researchrepository.wvu.edu/etd/1260

This Thesis is protected by copyright and/or related rights. It has been brought to you by the The Research Repository @ WVU with permission from the rights-holder(s). You are free to use this Thesis in any way that is permitted by the copyright and related rights legislation that applies to your use. For other uses you must obtain permission from the rights-holder(s) directly, unless additional rights are indicated by a Creative Commons license in the record and/ or on the work itself. This Thesis has been accepted for inclusion in WVU Graduate Theses, Dissertations, and Problem Reports collection by an authorized administrator of The Research Repository @ WVU. For more information, please contact researchrepository@mail.wvu.edu. 
Ant Colony Heuristics for the

Dynamic Facility Layout Problem

Jin Shang

Thesis submitted to the College of Engineering and Mineral Resources

at West Virginia University

in partial fulfillment of the requirements

for the degree of

Master of Science

in

Industrial Engineering

Alan R. McKendall, Jr., Ph.D., Chair

Bhaskaran Gopalakrishnan, Ph.D.

Wafik H. Iskandar, Ph.D.

Department of Industrial \& Management Systems Engineering

Morgantown, West Virginia

2002

Keywords: Ant Colony Heuristic, Dynamic Facility Layout 


\section{ABSTRACT \\ ANT COLONY HEURISTICS FOR THE DYNAMIC FACILITY LAYOUT PROBLEM \\ By Jin Shang}

As global economic competition and cooperation become more and more drastic, the enterprise's facility layout needs to be more flexible to adapt to the rapidly changing environment. Therefore, attention should be given to the dynamical nature of the facility layout. In other words, the flow of materials between departments changes during the planning horizon (multiple periods) and should be considered. This problem is known as the dynamic facility layout problem (DFLP).

This research proposes three heuristics based on the ant colony optimization (ACO) heuristic to solve the DFLP. The first one is a direct implementation of an ACO heuristic for the quadratic assignment problem to solve the DFLP (ACO I). The second heuristic uses the ACO I heuristic with a look-ahead and look-back strategy (ACO II). The third heuristic combines the ACO I heuristic with a simulated annealing (SA) heuristic (ACO III). The performance of the heuristics was evaluated using two data sets taken from the literature. Results obtained show that the proposed heuristics are effective for the dynamic facility layout problem. 


\section{ACKNOWLEDGEMENTS}

I express my deepest thanks to my advisor, Dr. Alan McKendall, Jr, who spent numerous hours to help me finish this thesis. He always gave me valuable guidance, comments and reviews. Under his help, I learned the approach to solve real world problems, and know what future work I should put emphasis on. Without his help, I could not have finished this research.

I am also grateful to my committee members, Dr. Wafik H. Iskandar and Dr. Bhaskaran Gopalakrishnan for their helpful comments and suggestions during this research.

Special thanks to the department of Industrial and Management Systems Engineering, West Virginia University, for providing me with good conditions for learning and conducting research.

Also, I would like to thank all my friends for their support and encouragement. Finally I extend my deepest thanks to my parents. 


\section{TABLE OF CONTENT}

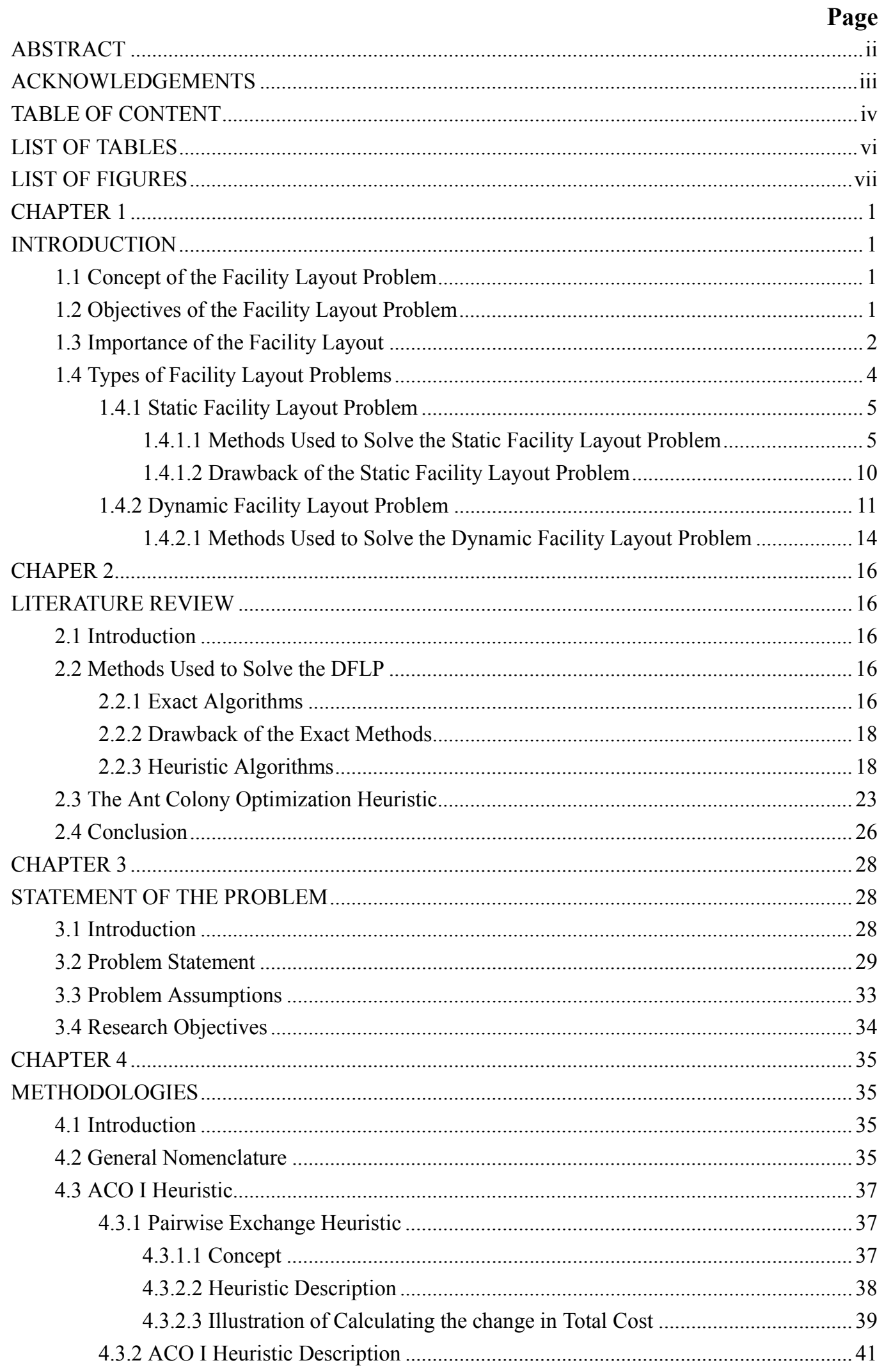


4.3.3 Illustration of the ACO I Heuristic ..................................................................... 45

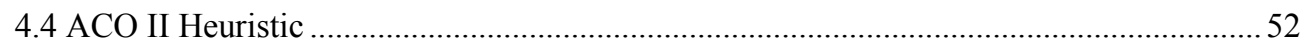

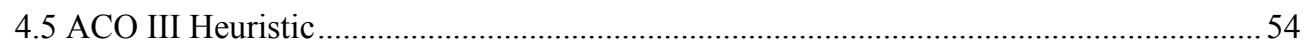

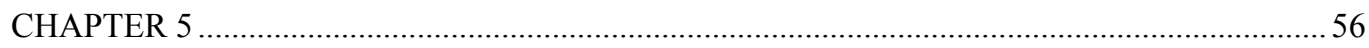

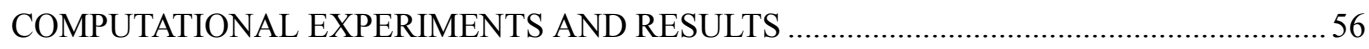

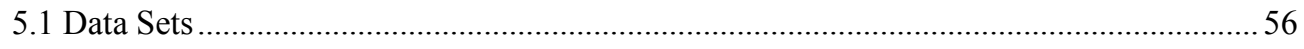

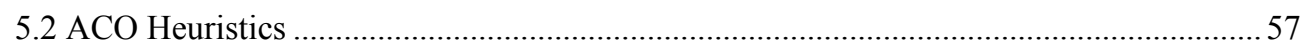

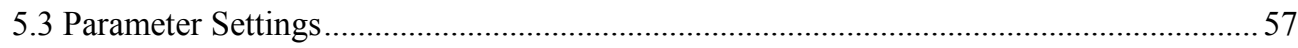

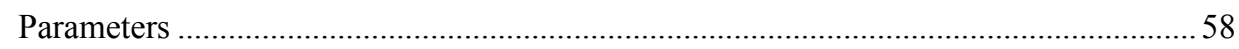

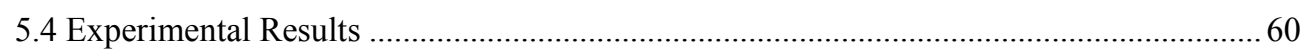

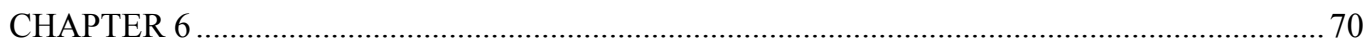

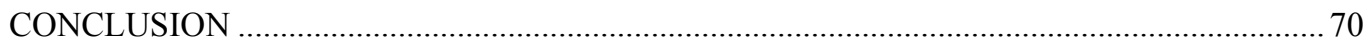

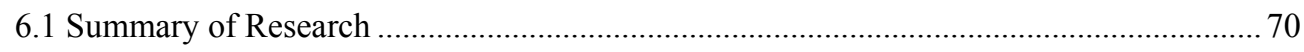

6.2 Recommendations for Future Research..................................................................... 70

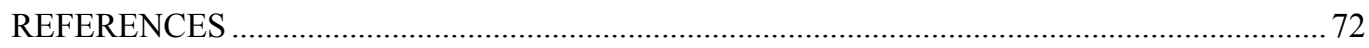




\section{LIST OF TABLES}

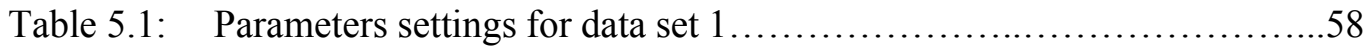

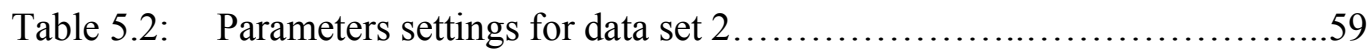

Table 5.3: $\quad$ Solution results for data set 1 ...................................62 \& 63

Table 5.4: $\quad$ Solution results for data set $2 \ldots \ldots \ldots \ldots \ldots \ldots \ldots \ldots \ldots \ldots \ldots \ldots \ldots$. $\& 65$

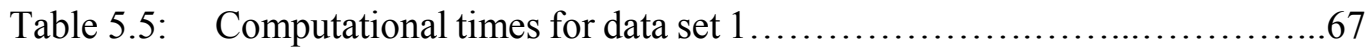

Table 5.6: Computational times for data set 2.............................68 \& 69 


\section{LIST OF FIGURES}

Figure 1.1: SFLP instance with 9 departments..............................

Figure 1.2: A DFLP instance with 4 departments and 3 time periods................12

Figure 3.1: Solution representation for a 6-department DFLP with 3 time periods...30

Figure 3.2: An example of a 6-department DFLP with 3 time periods................30

Figure 3.3: Solution representation for the DFLP instance in figure $3.2 \ldots \ldots \ldots \ldots . . .31$

Figure 3.4: Solution representation for a DFLP instance with $T=4$ and $M=2 \ldots \ldots .32$

Figure 4.1: $\quad$ Layout plan for a DFLP instance with $N=6$ and $T=4 \ldots \ldots \ldots \ldots \ldots . .40$

Figure 4.2: Time period and departments selected for exchange.................40

Figure 4.3: The layout plan after pairwise exchange.........................41

Figure 4.4: Material flow matrix for the DFLP instance........................46

Figure 4.5: Layout configuration for the DFLP instance .......................46

Figure 4.6: Distance matrix for the DFLP instance...........................46

Figure 4.7: The layout plan for the DFLP instance..........................5

Figure 4.8: Diagram of the look-ahead/look-back exchange procedure............53

Figure 4.9: The layout plan after the first iteration...............................5

Figure 4.10: Diagram of the SA heuristic ...................................55 


\section{CHAPTER 1}

\section{INTRODUCTION}

\subsection{Concept of the Facility Layout Problem}

The facility layout problem is encountered in a wide variety of areas. For example, facility layout techniques have been used in manufacturing facilities to reduce the total material handling cost. Also, layout techniques have been used in the layout of printed circuit boards to reduce the extent of the printed circuit pattern (Rockwell and Wilhelm, 1990).

The general facility layout problem is concerned with finding the most efficient non-overlapping arrangement of departments with unequal area requirements within a facility (Bozer and Meller, 1997). In the manufacturing context, facility layout may be defined as the process of obtaining the optimal disposition of the physical facilities for manufacturing units (El-Rayah and Hollier, 1970).

\subsection{Objectives of the Facility Layout Problem}

Usually, there are several typical objectives for the facility layout problem. The most widely used for the facility layout is based on: distance-based or adjacency-based objectives. The most common objectives of the facility layout problem are as follows (Bozer and Meller, 1997).

1) Minimize the financial cost in equipment and material cost. 
2) Meet the requirement of product design and volume.

3) Facilitate the manufacturing process.

4) Utilize existing space most effectively.

5) Make plant adaptive to future fluctuations.

6) Provide employees with a convenient, safe and healthy-environment.

Minimization of the material handling costs is a distance-based objective since it is based on the interdepartmental flows and distances between departments. An adjacency-based objective is based on departments' closeness ratings. The closeness rating is a numerical value, which indicates the preference between two departments being adjacent. By maximizing the adjacency score between preferred departments, the objective is achieved.

\subsection{Importance of the Facility Layout}

The facility layout plays a key role in the manufacturing process. The output of the facility layout problem is a block layout, which specifies the relative location of each department (Meller and Gau, 1996a). For instance, in manufacturing systems, material handling cost is one of the most important factors considered. The material handling cost can comprise between 30 and $70 \%$ of the total manufacturing cost (Sule, 1988). Because the material handling cost is proportional to the amount of material flow and the distances between the locations of the departments, the layout's efficiency can be measured in terms of material handling cost. 
In Meller and Gau (1996a), the authors discussed two kinds of surrogate material handling costs based on departmental adjacency relationships and interdepartmental distances (i.e., adjacency-based and distance-based costs). For adjacency-based costs, weights are used to assign departments with high interaction close or adjacent to each other. In other words, material handling cost is reduced significantly when two departments are adjacent. For distance-based costs, the material handling costs between two departments increase with the distance the unit load must travel between departments. The authors also mentioned that the distances could be measured in a variety of ways. The most common approaches for measuring the distances between departments are:

- Distance between input/output (I/O) points: the distance is measured between the specified I/O points of two departments and in some cases is measured along the aisles when moving between two departments.

- Centroid to centroid (CTC): when the I/O points of the departments are not known, the department centroid is used to represent the department's I/O point.

For each of the approaches used for measuring distances between departments, there are two commonly used methods for measuring the distance between two points (i.e., between two departments' locations):

- Rectilinear distance: based on travel distance along paths parallel to a set of perpendicular axes. 
- Euclidean distance: appropriate when distances are measured along a straight-line path connecting two points.

Any savings in material handling cost can be achieved through a better arrangement of the work-centers, departments or cells. This cost is a large portion of the total operating cost. If we can reduce these indirect costs, the company will become more competitive. As a result, the facility layout is a very key part in manufacturing. If the facility layout is efficiently arranged, the total operation cost will be decreased sharply.

\subsection{Types of Facility Layout Problems}

According to Lacksonen (1997), analysts divide a facility into practical divisions called departments and calculate the quantity of material flowing between pairs of departments. The author classified the following types of facility layout problems:

1) Job shop layout;

2) Cellular manufacturing layout;

3) Product layout;

4) Office layout;

5) Store layout; and

6) Warehouse layout;

This research focuses on the job-shop layout, where manufacturing facilities or departments are arranged such that material handling costs are minimized. When the 
flow of materials between facilities is fixed, the problem is known as the static facility layout problem.

\subsubsection{Static Facility Layout Problem}

As mentioned previously, the objective of the facility layout problem is to maximize an adjacency measure, minimize the material handling cost or optimize some combination of the two. For the static facility layout problem (SFLP), it is assumed that the flow of materials between departments does not change during the planning horizon. Based on the final layout design, a particular layout is executed and remains unchanged for the effective lifetime of the layout (Kochhar and Heragu, 1999).

\subsubsection{Methods Used to Solve the Static Facility Layout Problem}

A large number of procedures have been developed to solve the SFLP. These procedures can be classified into two main categories: construction type and improvement type. Basically, construction type layout methods involve developing a new layout from scratch. Improvement procedures generate layout alternatives based on an existing layout. Solution methods for both types of problems have been developed and these can be classified into three major groups (Yaman et al, 1993).

- Mathematical approaches.

- Heuristic methods. 
- Expert system solutions.

The mathematical approaches can be summarized under the following four categories:

1) Linear integer programming.

2) Mixed integer programming.

3) Quadratic assignment.

4) Quadratic set covering.

Heragu (1991) developed both linear continuous and linear mixed integer models for solving the SFLP with unequal size departments. To simplify this problem, it is often assumed that the sizes of the departments are equal. The reason for this assumption is that the facility layout problem with unequal size departments is an extremely difficult problem to solve. However, the following approach is used to solve large SFLPs with unequal size departments.

1) Solve the SFLP with equal size departments. The solution gives the relative location of the departments (i.e., determines which departments should be adjacent or close to each other).

2) Then by using these adjacency relationships, the unequal size departments can be assigned to locations within the facility such that the adjacency relationships and building constraints hold.

The facility layout problem with equal size departments is formulated as a quadratic assignment problem (QAP). The QAP is used to find the optimal layout for the SFLP from the set of all possible candidate layouts or permutations such that the 
total layout cost (material handling cost) is minimized. The QAP was first formulated by Koopmans and Beckman (1957). The objective of the QAP is to determine the best allocation of $n$ department to $n$ locations. Its application is popular in the real world, which includes layout planning of buildings on university campuses, arrangement of departments within hospitals, minimization of total wire length in electronic circuits, ordering of correlated data on magnetic tapes, as well as others (Burkard and Rendl, 1984). For example, figure 1.1 considers the potential locations for 9 departments within a manufacturing facility. The numbers represent the location number. Therefore, each rectangle represents a location. As a result, each of the 9 departments can be assigned to a location, and the distances between pairs of locations can be determined using the rectilinear distance measure between the centroids of the locations.

\begin{tabular}{|l|l|l|}
\hline 1 & 2 & 3 \\
\hline 4 & 5 & 6 \\
\hline 7 & 8 & 9 \\
\hline
\end{tabular}

Figure 1.1: SFLP instance with 9 departments.

The QAP for the SFLP can be formally presented as follows:

$$
\text { Minimize Cost }=\sum_{i=1}^{N} \sum_{j=1}^{N} \sum_{k=1}^{N} \sum_{l=1}^{N} f_{i k} d_{j l} x_{i j} x_{k l}
$$

Subject to: 


$$
\begin{aligned}
& \sum_{j=1}^{N} x_{i j}=1, i=1, \ldots, N \\
& \sum_{i=1}^{N} x_{i j}=1, j=1, \ldots, N \\
& x_{i j}=\{0,1\}, i, j=1, \ldots, N
\end{aligned}
$$

where

$N=$ Number of departments and locations.

$f_{i k}=$ Flow of materials between facilities (departments) $i$ and $k$ (assuming that $f_{i i}=0$ for all $\left.i\right)$.

$d_{j l}=$ Distance between locations $j$ and $l$ (assuming that $d_{j j}=0$ for all $j$ ).

$x_{i j}=\left\{\begin{array}{l}1, \text { if department } i \text { is assigned to location } j \\ 0, \text { otherwise }\end{array}\right.$

The objective function (1) is used to minimize the total distance materials travel.

Constraint set (2) ensures that one location is assigned to each department, and constraint set (3) ensures that exactly one department is assigned to each location.

Bazaraa (1975) used the quadratic set covering problem (QSCP) to model accurately the SFLP with unequal size departments. The typical QSCP approach divides the available departments into small equal size blocks. When this approach is applied to the SFLP, the department is divided into equal area unit rectangular blocks.

By modeling the SFLP mathematically, the optimal layout can be obtained. The QAP model can be solved optimally by the following exact methods:

- Branch and bound techniques; and

- Cutting Plane methods

QAPs with more than 20 departments cannot be solved in acceptable time 
(Burkard et al., 1997). Although computer speeds have improved drastically between 1997 and 2002, the computational effort grows exponentially; therefore, this problem is computationally intractable, and large size problems cannot be solved in reasonable time. Since many real world problems require solving QAPs with more than 20 departments, more recently, heuristics have been proposed which can overcome the limitations of exact methods. Although the solutions obtained from these heuristics are often not optimal, the results obtained are good and are obtained in acceptable computation time. The typical heuristic methods used to solve the SFLP are as follows:

- Pairwise exchange

- Tabu search

- Ant colony

- Simulated annealing

- Artificial neural networks

- Genetic algorithms

Expert system applications to the facility layout problem began in the mid-1980s. These methods enable a new approach to the problem, because they have provision for calculation advantage and may incorporate expert knowledge to deal with subjective aspects of the SFLP (Yaman et al., 1993). 


\subsubsection{Drawback of the Static Facility Layout Problem}

For the SFLP, it is assumed that material flow between departments remains constant during the planning horizon. If there are changes in the material flow, these changes are determined during the planning stage prior to the design stage. However, in today's manufacturing environment, products change frequently, and it is not possible to correctly predict this change for long time periods (Kochhar and Heragu, 1999). In other words, when there are product changes, the layout of the facility may need to be rearranged and the length of time during which a layout is feasible and/or optimal cannot be determined. Furthermore, with the global market and high global competition, many new technologies are developed so that manufacturing plants are more flexible and operate more efficiently. Therefore, there are several major factors which may impact the layout of a facility and some of them are: applying a new technology to existing products, changing the volume of a product, or adding or deleting some new products, etc. These changes will be discussed further in the next section. Any of these changes usually results in redesigning the layout, since the current layout usually gives high material handling cost.

In this research, arranging and rearranging the layout of facilities for multiple time periods during a planning horizon (i.e., when the flow between departments changes) is considered. This problem is known as the dynamic facility layout problem. If the layout planner of a facility does not consider rearranging the departments when there are changes as defined above, the current layout can be extremely costly. Therefore, the SFLP assumes that there are no changes and does not consider the 
dynamic environment.

\subsubsection{Dynamic Facility Layout Problem}

Hitchings (1970) first discussed and reported on the dynamic nature of the layout design problem. For the constantly changing attributes in the manufacturing system, there is a need to consider a flexible layout, which can handle future scenarios (Shore and Tompkins, 1980).

Generally, changes in the flow are the results of many factors (Kuppusamy, 2001, p. 41) such as:

- The change in the design of an existing product;

- The elimination of products from a product line;

- The introduction of new products;

- Replacements of existing production equipments;

- Shorter life cycle products; and

- Changes in the production quantities and associated production schedule.

Rosenblatt (1986) defined and solved the dynamic facility layout problem (DFLP). He assumed a deterministic environment where the number of orders and quantities, and the production date for every product was known for a given finite horizon. Also, at each time period in the planning horizon, the material handling cost and the rearrangement costs are determined. Rearrangement costs are the cost of changing the locations of departments between consecutive time periods. Simply 
stated, if the layout between consecutive periods changes (i.e., the location of two or more departments change), then the cost of moving departments from one location to another is determined; and this cost is called rearrangement cost. Of course, this method assumes that material flow can be predicted accurately. If the future material flows and department rearrangement cost can be reasonably estimated, then this problem is dynamic and can be solved by modeling the problem as a DFLP. Initially, this problem was solved as a SFLP for each time period in the planning horizon, but solving a series of SFLPs does not consider rearrangement cost. Hence, this approach produces poor solutions for the DFLP.

\begin{tabular}{|l|l|}
\hline 1 & 3 \\
\hline 2 & 4 \\
\hline
\end{tabular}

$t=1$

\begin{tabular}{|l|l|}
\hline 1 & 4 \\
\hline 2 & 3 \\
\hline
\end{tabular}

$t=2$

\begin{tabular}{|l|l|}
\hline 1 & 4 \\
\hline 2 & 3 \\
\hline
\end{tabular}

$t=3$

Figure 1.2: A DFLP instance with 4 departments and 3 time periods.

The flow data (i.e., the flow of materials between departments) for each period is known with certainty, and it is assumed that the flow data remain constant throughout the period. A layout plan for the DFLP is a series of layouts, and each layout is associated with a period. Therefore, the layout for each period in the planning horizon can be obtained by solving the SFLP for each period. For instance, consider the DFLP instance in figure 1.2. In the first time period (i.e., $t=1$ ), departments $1,3,2$, and 4 
are assigned to locations $1,2,3$, and 4, respectively. The layout at this time period can be represented as the permutation $(1,3,2,4)$ where departments 1 and 3 are assigned to locations 1 and 2, respectively, and so on. Since departments 3 and 4 are assigned to different locations (i.e., locations 4 and 2 , respectively) in time period 2, rearrangement costs are incurred and are the costs of moving department 3 from location 2 to location 4 plus the cost of moving department 4 from location 4 to location 2. Because the layout is the same in time periods 2 and 3 , there is no rearrangement cost in time period 3. Also the material handling costs for each period is determined using the flow matrices for each time period and the distances between locations (i.e., distance matrix). Therefore, the DFLP is the problem of efficiently arranging the departments within a facility during a multi-period planning horizon such that the sum of material handling and rearrangement costs is minimized.

The formulation of the DFLP with equal size departments is given below and is adapted from Balakrishnan et al. (1992).

Minimize Cost $=\sum_{i=1}^{N} \sum_{j=1}^{N} \sum_{l=1}^{N} \sum_{t=2}^{T} A_{i j l t} Y_{i j l t}+\sum_{i=1}^{N} \sum_{j=1}^{N} \sum_{k=1}^{N} \sum_{l=1}^{N} \sum_{t=1}^{T} C_{i j k l t} X_{i j t} X_{k l t}$

Subject to

$$
\begin{aligned}
& \sum_{j=1}^{N} X_{i j t}=1, i=1, \ldots, N \text { and } t=1, \ldots, T \\
& \sum_{i=1}^{N} X_{i j t}=1, j=1, \ldots, N \text { and } t=1, \ldots, T \\
& Y_{i j l t}=X_{i j(t-1)} * X_{i l t} \quad i, j, l=1, \ldots, N, \quad t=2, \ldots T \\
& X_{i j t}=\{0,1\}, i, j=1, \ldots, N, \quad t=1, \ldots T \\
& Y_{i j l t}=\{0,1\}, i, j, l=1, \ldots, N, \quad t=1, \ldots T
\end{aligned}
$$


where

$N=$ Number of departments and locations.

$T=$ Number of time periods.

$A_{i j l t}=$ Cost of shifting department $i$ from location $j$ to $l$ in period $t\left(A_{i j j t}=0\right)$.

$C_{i j k l t}=$ Cost of material flow between department $i$ located at location $j$ and $k$ located at $l$ in period $t$.

$X_{i j t}=\left\{\begin{array}{l}1, \text { if department } i \text { is assigned to location } j \text { at period } t \\ 0, \text { otherwise }\end{array}\right.$

$Y_{i j l t}=\left\{\begin{array}{l}1, \text { if department } i \text { is shifted from location } j \text { to } l \text { at the beginning of period } t \\ 0, \text { otherwise }\end{array}\right.$

The objective function (1) is used to minimize the sum of the rearrangement and flow costs between the departments. Constraint set (2) ensures that each location is assigned only one department at each time period, and constraint set (3) ensures that exactly one department is assigned to each location at each time period. Constraint set (4) helps to add the rearrangement costs to the material flow cost if a department is shifted between locations in consecutive periods. This model considers the flow between the departments, distances between locations and rearrangement costs as inputs.

\subsubsection{Methods Used to Solve the Dynamic Facility Layout Problem}

Most of the formulations of the DFLP are extensions of the QAP used for the SFLP. The difference between the QAP for the DFLP and the SFLP is that the QAP 
for DFLP does not only consider material handling cost, but also consider the rearrangement costs between consecutive time periods.

There are also several algorithms used to solve the DFLP. They can be classified as exact and heuristic methods. The typical exact method is:

- Dynamic programming

By using an exact method to solve the DFLP, optimal solutions can be obtained. However, computational time for solving the DFLP using exact methods is intractable, even for small-size DFLPs. Therefore, heuristic methods are used to solve realistic size DFLPs. Although the heuristic methods cannot guarantee optimal solutions, good solutions are generated very quickly. The most common heuristic methods used to solve the DFLP are:

- Pairwise exchange;

- Cutting plane;

- Branch and bound techniques;

- Cutting trees;

- Genetic algorithms;

- Tabu search; and

- Simulated annealing.

These methods will be discussed further in Chapter 2. 


\section{CHAPER 2}

\section{LITERATURE REVIEW}

\subsection{Introduction}

Currently there is a trend of shorter cycle times and greater volatility in product variety and design. Therefore, researchers have recently begun to focus on the DFLP. If the number of periods $T$ and the number of departments $N$ are considered, the maximum number of permutations (i.e., possible layout plans) for the DFLP that needs to be considered is $(N !)^{T}$. For even very small size problems, it is computationally difficult to obtain the optimal layout plan. The techniques for solving the DFLPs are discussed below.

\subsection{Methods Used to Solve the DFLP}

\subsubsection{Exact Algorithms}

Rosenblatt (1986) used dynamic programming to solve the DFLP. The optimal solutions can be obtained by starting in the last time period and finding the static optimal layout at each time period using a recursive relationship function. Before solving the problem, the deterministic environment is assumed, which means that all the numbers of orders and the quantities, as well as production dates for products are known for a given finite horizon. Although an optimal solution can be obtained from 
the recursive relationship established by the author, by considering all possible layouts for each period, computational time increases exponentially as the problem size increases (i.e., as the number of departments and time periods increases, the computational time increases exponentially). Therefore, Rosenblatt provided a heuristic procedure, which includes two approaches. One is similar to Ballou's (1968) heuristic for the warehouse location problem. This method considers using only the best layout for each period, which is obtained from solving the SFLP for each period. The number of layouts that needs to be considered is decreased greatly. The other is CRAFT (Armour and Buffa, 1963) or COFAD (Tompkins and Reed, 1976) for SFLP, which is used to generate sets of layouts for different periods. Both of these approaches reduce the maximum number of layouts needed to be considered, which makes the problem tractable.

Lacksonen and Enscore (1993) used the QAP formulation for the DFLP and modified five algorithms used to solve the QAP for the SFLP so that they can be applied to the DFLP. Two of these algorithms, dynamic programming and branch and bound are exact methods. The authors used the dynamic programming algorithm presented by Rosenblatt (1986). Pardalos and Crouse (1989) presented a branch and bound algorithm for solving the QAP optimally, which uses the cutting plane algorithm discussed below (in section 2.2.3) to obtain a good upper bound on the total cost. Each node in the tree represents a partial assignment with a lower bound on cost. Two modifications were made to this algorithm to solve the DFLP. First, departments were only permitted to be assigned to the proper time period. Second, the lower bound 
was calculated by considering the cost of all the time periods which do not have any assignments yet made. Since the DFLP is computationally intractable, in practical application (i.e., medium to large size problems), the exact algorithms are modified and used as heuristics. In other words, the dynamic programming algorithm does not consider all possible layouts (states) at each stage, and the branch and bound algorithm terminates after a certain number of iterations. Therefore, these exact methods did not produce the optimal or even the best solutions for large size problems.

\subsubsection{Drawback of the Exact Methods}

As mentioned previously, the exact methods can only solve smaller size problems in reasonable time. The simple QAP with more than 20 departments cannot be solved in acceptable time (Burkard et al., 1997). Since the DFLP is a generalization of the QAP, it is much more difficult to solve. Recall that solving the DFLP requires solving a series of QAPs. Although using exact methods can produce optimal solutions, it is feasible only for small size problem. That is, exact methods can only be used to solve extremely small problem in reasonable computational time.

\subsubsection{Heuristic Algorithms}

Lacksonen and Enscore (1993) modified three heuristic algorithms (CRAFT, cutting trees and cutting planes) used to solve the QAP for the SFLP, so that they can 
be applied to the DFLP. CRAFT, presented by Armour and Buffa (1963), starts with a random layout and exchange the locations of pairs of departments to reduce total material handling cost. The authors extended this heuristic to solve the DFLP. This heuristic, which is called the pairwise exchange heuristic, will be discussed in Chapter 4. The cutting tree heuristic presented by Gomory and Hu (1961), is a spanning tree where the arc of minimum weight on the path between two nodes in the tree corresponds to the weight of the min-cut separating the two nodes in the original graph. Lacksonen and Enscore extended and used the cutting plane heuristic presented by Burkard and Bonniger (1983) to solve the DFLP. In this heuristic, the QAP is solved by combining cutting planes with an exchange routine in an iterative heuristic. To solve the DFLP, the cutting plane portion in this heuristic assumes that the layouts for all the time periods are the same. Then, it only considers rearrangements in its exchange routine.

Urban (1993) developed a steepest-descent pairwise-interchange procedure to solve the DFLP, similar to CRAFT. The difference is that rearrangement costs and the concept of forecast windows are included. The main idea was to use forecast windows for the DFLP to allow a layout arrangement to be used for any given block of periods, avoiding rearrangement costs. This heuristic first analyzes the problem at each planning horizon period as a SFLP. The length of the forecast windows, $m$, vary between 1 and the number of time periods. When $m=1$, the flow data for time period 1 is used to generate a layout for that period, and the flow data for period 2 is used to obtain a layout for period 2. This process is continued until a layout is generated for 
all the time periods with $m=1$. After obtaining a layout for each period in the planning horizon, set $m=2$. For $m=2$, the flow data for time periods 1 and 2 are used to generate a layout for time period 1 . The flow data for time periods 2 and 3 are used to obtain a layout for time period 2 and so on. If the total number of time periods is $5(T=5)$, only the flow data for time period 5 is used to generate the layout for time period 5 when $m=2$. Also, for $m=3$ and $T=5$, flow data for time periods 4 and 5 are used to obtain a layout for time period 4. The length of the forecast window is incrementally extended until it equals the entire planning horizon. As a result, $m$ layout plans are given for $m$ time windows. Furthermore, the $m$ layout plans are improved by using a pairwise exchange heuristic. This heuristic decreases the computational complexity and usually obtains good solutions even for large size problems. Finally, the author compared the results obtained from the proposed heuristic with results obtained using dynamic programming as presented by Rosenblatt (1986), specifically, Ballou's heuristic and two random methods (i.e., methods that randomly generated 10 and 20 layouts in each period of the dynamic programming model). Computational results show that Ballou's heuristic appears to perform slightly better than the Urban's heuristic for small size problems. However, for large size problems, Ballou's heuristic was unable to obtain solutions in reasonable computational time. Also, Urban's heuristic gave better solutions than Rosenblatt's random heuristics.

Conway and Venkataramanan (1994) utilized a genetic algorithm (GA) to solve the DFLP. The main idea of the authors' GA heuristic is to first randomly generate 
feasible solutions (layout plans), called strings, and assign a fitness value (i.e., obtain the cost of the layout plan). Two solutions (strings) are selected using the "roulette wheel" scheme. These solutions are crossbred in a predetermined way to produce two more solutions. To avoid getting trapped at a local optimum, some of the solutions are mutated (i.e., slightly changed) before crossbreeding. The authors utilized the GA to solve the data set given in Rosenblatt (1986) and obtained better solutions. One of the major drawbacks of this method is that infeasible solutions can be generated while crossbreeding, and additional swaps are performed to ensure feasibility.

Balakrishnan, Cheng, and Conway (2000) proposed an improved pairwise exchange heuristic for the DFLP. Two improvements were proposed for the steepest descent pairwise exchange heuristic presented by Urban (1993). The first one involves working backwards from the final solutions obtained for each value of $m$, the length of forecast window. Since Urban's heuristic is naturally a forward pass heuristic, the final solution depends on the preceding layouts greatly. Therefore, this is considered as a drawback in the proposed heuristic. The second heuristic presented by the authors included combining Urban's pairwise exchange heuristic with dynamic programming. The modified pairwise exchange heuristics proposed by the authors out-performed Urban's heuristic.

Balakrishnan and Cheng (2000) proposed a nested loop GA, which is different from the GA heuristic presented by Conway and Venkataramanan (1994). The authors stated that their GA differs in three aspects: they employ a different crossbreeding method to increase the search space; mutation is used to increase population diversity; 
and they use a generational replacement approach to increase population diversity. Computational results show that the authors GA out-performs the GA presented by Conway and Venkataramanan (1994), especially for large size problems.

Kaku and Mazzola (1997) presented a tabu search (TS) heuristic to solve the DFLP. The TS heuristic is a two-stage search process that incorporates the diversification and intensification strategies. Three diversification strategies were utilized: random generation of initial layouts, generation of initial layouts using a construction heuristic, and the implementation of a frequency-based tabu criterion. The intensification strategy was implemented though the adaptive tabu list (dynamic tenure length). The authors used the data set presented by Lacksonen and Enscore (1993) to test their TS heuristic, and the results were compared with the best-known solutions in the literature obtained by the heuristics presented by Lacksonen and Enscore (1993) and Urban (1993). The results show that the TS heuristic is superior when the problem size increases.

Baykasoglu and Gindy (2001) presented a simulated annealing (SA) heuristic to solve the DFLP. SA is a stochastic neighborhood search method developed for combinatorial optimization problems. The main idea of this algorithm is that it can avoid getting trapped at a local optimum by accepting uphill moves (non-improving solutions) with some probability based on the difference in the objective function values of the non-improving and the current solutions. This probability is also determined by a controlling parameter called the temperature, which decreases during the SA procedure. The authors tested their SA heuristic on the data set given in 
Balakrishnan and Cheng (2000). The results show that the SA algorithm performs much better than the GAs presented in Conway and Venkataramanan (1994) and Balakrishnan and Cheng (2000) for large size DFLPs.

Kuppusamy (2001) proposed three simulated annealing heuristics for the DFLP. The first is the direct implementation of the simulated annealing algorithm. The second heuristic uses a reheating strategy within simulated annealing. The third heuristic combines the simulated annealing algorithm, time windows concept, and the backward pairwise exchange method. The computational experiments were conducted on the data set provided by Lacksonen and Enscore (1993). The performance of the heuristics was evaluated using two measures: solution quality and computational time. Results obtained show that the proposed heuristics are effective for the DFLP.

\subsection{The Ant Colony Optimization Heuristic}

Dorigo et al. (1996) presented heuristics, which use artificial ants, to solve traveling salesperson problems, the QAP, and the job shop scheduling problem. They are called ant colony optimization (ACO) heuristics. These heuristics simulate how ants search for food, in order to find solutions. The authors discuss how ants are capable of finding the shortest path from a food source to the nest without using visual cues. In searching for food, the ants do not communicate directly but indirectly by adding a chemical trail (called pheromone trail) to the environment. Initially, ants explore the areas surrounding their nest in a random manner. The shortest path 
between a food source and the nest is determined based on the pheromone trail an ant leaves while returning back to the nest from the food source so that other ants can find the food source. The amount of the pheromone trail left by an ant is based on the amount of food found. If the paths between the food source and the nest are far apart, fewer ants will travel these paths, and the trail will eventually evaporate. However, when the path between the food source and the nest are close, more ants will travel this path, which will be indicated by a strong pheromone trail.

In ACO heuristics, the ant is defined as a simple computational agent, which iteratively improves or constructs a solution for a combinatorial optimization problem. The main traits of artificial ants are taken from real ants and their natural behavior. The main traits are as follows: (1) artificial ants exist in colonies of cooperating individuals, (2) they communicate indirectly by depositing (artificial) pheromone, (3) they use a sequence of local moves to find the shortest path from a starting point to a destination (i.e. the optimal solution), and (4) they apply a stochastic decision policy using local information only (i.e. they do not look ahead) to find good solutions.

Informally, pheromone levels measure how desirable it is to insert a given element into a solution (e.g., inserting a city in a tour while constructing a solution for the traveling salesperson problem). Pheromone trails are maintained in a matrix called the pheromone matrix. After constructing a new solution, the pheromone trails can be updated as follows: 1) all the pheromone trails are decreased to simulate the evaporation of pheromone and 2) the pheromone trails corresponding to components that were in the best solution found so far are reinforced, taking into consideration the 
quality of the solution. Dorigo and Gambardella (1997b) also presented similar heuristics for solving the traveling salesperson problem.

Gambardella et al. (1999) presented an ACO heuristic called the hybrid ant colony system to solve the QAP (HAS-QAP). HAS-QAP is different from the traditional ACO heuristic, since it is an improvement heuristic instead of a construction one. First, a set of solutions is generated randomly such that each solution (i.e., layout plan) is represented by an ant. The set of solutions is improved by using a local search technique, and the best solution is obtained and used to initialize the pheromone trail matrix. The entries in the pheromone trail matrix $P, p_{i j}$, measures the desirability of assigning department $i$ to location $j$. These entries are used to determine which department locations should be exchanged (or swapped). These swaps are called pheromone trail swaps and are performed as follows: select department $r$, randomly between 1 and $N$ (number of departments) and select a second department $s \neq r$ according to one of the policies.

1) With a probability $q, s$ is chosen such that $p_{r, \pi_{s}}+p_{s, \pi_{r}}$ is maximized $\left(\pi_{r}=\right.$ location of department $r$ ). This policy consists of exploiting the pheromone trail.

2) With a probability $1-q, s$ is chosen with probability $\frac{p_{r, \pi_{s}}+p_{s, \pi_{r}}}{\sum_{j \neq u}\left(p_{r, \pi_{j}}+p_{j, \pi_{r}}\right)}$. This policy consists of exploring the solution space by choosing the second department $s$ with a probability proportional to the values contained in the pheromone trail.

After performing trail swaps for each ant, a local search technique is used to improve the solutions. If the best solution obtained thus far has improved (or at the start of the heuristic), an intensification scheme is activated. When intensification is 
active, the best solution between the solution at the start of the iteration and the solution obtained after the local search technique is used to start the next iteration. Otherwise, the initial solution at the next iteration is the improved solution obtained using the local search technique. Intensification remains active while at least one ant improves its solution during an iteration. The function of the intensification scheme is to explore the neighborhood of good solutions more completely.

Once the starting solution for the next iteration is obtained for each ant, the pheromone trail matrix is updated using the best solution obtained thus far. When updating the matrix, the pheromone trails are first weakened, and certain trails are strengthened based on the best-found solution. Also, a diversification mechanism is activated if a certain number of iterations is performed without improvement to the best found solution. When this strategy is invoked, all of the information is erased. That is, an initial set of solutions is randomly generated (use best ant or solution obtained previously), the pheromone trail matrix is re-initialized, and the technique is started from scratch. The diversification strategy is used to explore the solution space more thoroughly to obtain diverse solutions. The numerical results show that the HAS-QAP heuristic obtained very good results for the QAP.

\subsection{Conclusion}

The above literature review shows that there is a lot of research being performed on the DFLP, and that the ACO heuristic, HAS-QAP, is a good heuristic for solving the QAP for the SFLP. Since this new heuristic algorithm has not been applied to the 
DFLP problem, this research will use the ACO heuristic (HAS-QAP) to solve the DFLP. 


\section{CHAPTER 3}

\section{STATEMENT OF THE PROBLEM}

\subsection{Introduction}

Within a manufacturing system, any change related to the layout of a facility will have great influence on the total operating cost. This means that if the layout is inefficient, the total cost will be increased greatly because material handling cost can account for $30 \%$ to $70 \%$ of the total operating costs. In addition, the material flow between departments will be chaotic, even circuitous.

In the dynamic environment, the flow between departments changes with time. When this happens, the layout of the departments should be redesigned to meet the goal of minimizing material handling cost. If the layout in different time periods is different, then rearrangement costs should be considered. Usually, the rearrangement cost results from moving machines from their original locations to their new locations. Of course, costs related to planning, dismantling, installation and shutdowns should be considered when calculating the rearrangement cost. Therefore, in the DFLP, the total cost is the sum of the material handling and rearrangement costs for all time periods.

Lacksonen and Enscore (1993) state two limiting cases for the DFLP. First, when the rearrangement costs are much higher than the flow costs, the flows for each time period can be summed up, and the problem is solved as a SFLP. Second, when the converse happens, the DFLP can be solved as a series of independent SFLPs, since 
the rearrangement costs are negligible. This research avoids these two extreme cases.

\subsection{Problem Statement}

This research focuses on the DFLP with equal size departments. For the DFLP, the solution or layout plan is a series of layouts for each time period during the planning horizon. This research focuses on finding the best set of permutations or layout plans for the DFLP such that sum of the material handling and rearrangement costs for all time periods is minimized.

If $\pi_{t}$ is used to represent the layout for each time period $t$ for the DFLP with $N$ departments and $T$ time periods, then the solution obtained from solving this DFLP can be represented as the following set of permutations:

$$
\pi=\left\{\pi_{1}, \pi_{2,}, \ldots, \pi_{T}\right\}
$$

where $\pi_{t}$, for $t=1,2, \ldots, T$, can be represented as a permutation of the departments for time period $t$. Then, $\pi_{i t}$ represents the department assigned to location $i$ at time period $t$ :

$$
\pi_{t}=\left\{\pi_{1 t,} \pi_{2 t}, \ldots, \pi_{N t}\right\}
$$

For example, $\pi_{3}=\{2,3,1,4\}$ shows that department 2 is assigned to location 1 at time period 3 (i.e., $\pi_{13}=2$ ) and department 3 is assigned to location 2 at time period 3 (i.e., $\pi_{23}=3$ ), etc. Hence,

$$
\pi=\left\{\left(\pi_{11}, \pi_{21}, \ldots, \pi_{N 1}\right),\left(\pi_{12}, \pi_{22}, \ldots, \pi_{N 2}\right), \ldots,\left(\pi_{1 T}, \pi_{2 T}, \ldots, \pi_{N T}\right)\right\} .
$$

See figure 3.1 for an example of a solution representation for a specific DFLP instance (i.e., a 6-department problem with 3 time periods). More importantly, see 
figure 3.2 for a layout plan for the DFLP instance.

$\begin{array}{ll}\text { Time period 1 } & \pi_{1}=\left\{\pi_{11}, \pi_{21}, \pi_{31}, \pi_{41}, \pi_{51}, \pi_{61}\right\} \\ \text { Time period } 2 & \pi_{2}=\left\{\pi_{12}, \pi_{22}, \pi_{32}, \pi_{42}, \pi_{52}, \pi_{62}\right\} \\ \text { Time period } 3 & \pi_{3}=\left\{\pi_{13}, \pi_{23}, \pi_{33}, \pi_{43}, \pi_{53}, \pi_{63}\right\} \\ \end{array}$

Figure 3.1: Solution representation for a 6-department DFLP with 3 time periods.

\begin{tabular}{|l|l|l|}
\hline 1 & 2 & 3 \\
\hline 4 & 5 & 6 \\
\hline
\end{tabular}

$t=1$

\begin{tabular}{|l|l|l|}
\hline 2 & 1 & 3 \\
\hline 4 & 5 & 6 \\
\hline
\end{tabular}

$$
t=2
$$

\begin{tabular}{|c|c|c|}
\hline 2 & 3 & 1 \\
\hline 4 & 6 & 5 \\
\hline
\end{tabular}

$t=3$

Figure 3.2: An example of a 6-department DFLP with 3 time periods.

In figure 3.2, the number in the rectangle represents the department. For instance, in time period 2, department 1 is assigned to location 2 and department 4 is assigned to location 4. According to the solution representation technique mentioned above, a set of permutations (i.e., a layout plan or a solution) for the DFLP instance in figure 3.2 is shown in figure 3.3 . 


$$
\begin{array}{ll}
\text { Time period } 1 & \pi_{1}=\{1,2,3,4,5,6\} \\
\text { Time period } 2 & \pi_{2}=\{2,1,3,4,5,6\} \\
\text { Time period } 3 & \pi_{3}=\{2,3,1,4,6,5\}
\end{array}
$$

Figure 3.3: Solution representation for the DFLP instance in figure 3.2.

Hence, the layout plan or set of permutations for the DFLP instance given in the example above (i.e., in figure 3.3) is

$$
\pi=\{(1,2,3,4,5,6),(2,1,3,4,5,6),(2,3,1,4,6,5)\} .
$$

In most of the heuristic methods used to solve the DFLP, the pairwise exchange heuristic method is used. In this method, at a specific time period $t$, the locations of two departments $u$ and $v$ are selected for exchange. In other words, $\pi_{u t}$ and $\pi_{v t}$ are exchanged in the permutation $\pi_{t}=\left\{\pi_{1 t}, \pi_{2 t}, \ldots, \pi_{u t}, \ldots, \pi_{v t}, \ldots, \pi_{N t}\right\}$, which results in the new permutation $\pi_{t}^{\prime}=\left\{\pi_{1 t}, \pi_{2 t}, \ldots, \pi_{v t}, \ldots, \pi_{u t}, \ldots, \pi_{N t}\right\}$. For instance, consider $\pi_{3}=\{2,3,1,4\}$ where the locations of departments 3 and 1 are selected for exchange. After the exchange, the permutation $\pi_{3}$ becomes $\{2,1,3,4\}$. Then, the sum of the material handling costs and rearrangement costs are calculated as follows:

$$
f(\pi)=\sum_{i=1}^{N} \sum_{j=1}^{N} \sum_{t=1}^{T} a_{\pi_{i t}, \pi}, t, b_{i j}+\sum_{i=1}^{N} \sum_{t=2}^{T} c_{\pi_{i t}} * x_{i t}
$$

where

$f(\pi)$ is the sum of the material handling and rearrangement costs;

$a_{\pi_{i t}, \pi_{j t}, t}$ is the material flow from department $\pi_{i t}$ to $\pi_{j t}$ at time period $t$;

$b_{i j}$ is the distance between locations $i$ and $j$; 
$c_{\pi_{i t}}$ is the rearrangement cost for department $\pi_{i t}$; and

$x_{i t}=\left\{\begin{array}{l}1 \text { if } \pi_{i t} \text { is not equal to } \pi_{i(t-1)} \\ 0 \text { otherwise }\end{array}\right.$

In this research, three ACO heuristics are presented for the DFLP. The first heuristic (ACO I) is a modification of the HAS-QAP heuristic for the QAP. The second heuristic (ACO II) is a combination of the ACO I heuristic with a look-ahead and look-back mechanism. The third heuristic (ACO III) is a combination of the ACO I heuristic and a SA heuristic for the DFLP.

Since the ACO heuristics require an initial set of solutions (or a colony of ants) as opposed to an initial single solution, the solution representation is extended to consider multiple solutions simultaneously. First, $m$ initial solutions (i.e., $\left.\pi^{1}, \pi^{2}, \ldots, \pi^{m}\right)$ are generated and are associated with $m$ ants. The solution structure is a cubic, and an example is given in figure 3.4.

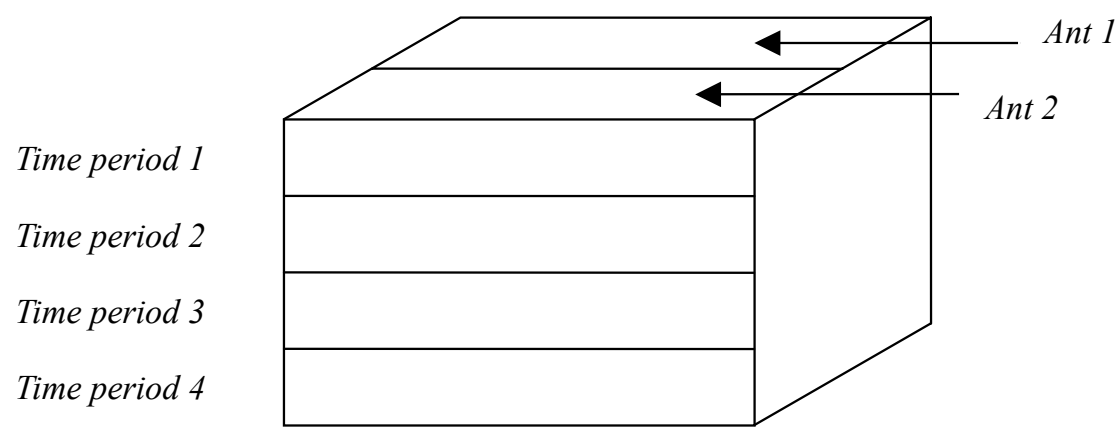

Figure 3.4: Solution representation for a DFLP instance with $T=4$ and $M=2$. 
The $m$ solutions obtained, $\pi^{1}, \pi^{2}, \ldots, \pi^{m}$, are improved by using a local search heuristic, and the best solution is used to initialize the pheromone trail matrix. Then, by using the pheromone trail swaps for each ant, different solutions (called neighboring solutions) are generated. These solutions will be improved by using a local search heuristic. The purpose for this is to allow the technique to accept worst solutions (i.e., allow uphill moves) so that the heuristic does not converge to a poor local optimum. If the best-found solution is improved, an intensification strategy is invoked. After so many iterations without improvement to the best solution, a diversification strategy is implemented, and the heuristic is repeated until the stopping criterion is satisfied.

\subsection{Problem Assumptions}

The assumptions for the DFLP are as follow:

1. The basic configuration of the layout is known.

2. The distances and rearrangement costs between departments are determined $a$ priori.

3. Flow between departments is dynamic and deterministic (i.e., known with certainty).

4. Departments and locations are of equal size.

5. The initial assignment cost of a department to a location is ignored but can easily be considered. 


\subsection{Research Objectives}

The major objectives of this research are as follows:

- To develop ACO heuristics to obtain good solutions for the DFLP.

$\diamond$ ACO I (a modification of the HAS-QAP heuristic for the QAP).

$\diamond$ ACO II (the ACO I heuristic with a look-ahead and look-back mechanism).

$\diamond$ ACO III (a combination of the ACO I heuristic with a SA heuristic).

- To evaluate the proposed ACO heuristics by comparing their results to results obtained from the best-known heuristics in the literature. 


\section{CHAPTER 4}

\section{METHODOLOGIES}

\subsection{Introduction}

Dorigo et al. (1996) initiated the idea of imitating the behavior of ants when they forage for food to solve combinatorial optimization problems. The HAS-QAP heuristic used to solve the QAP for the SFLP was presented by Gambardella et al. (1999). However, until now, this heuristic was never applied to the DFLP. In this research, three ACO heuristics are used to solve the DFLP by modifying the HAS-QAP heuristic. The first heuristic (ACO I) is a modification of the HAS-QAP heuristic for the QAP. The second heuristic (ACO II) is a combination of the ACO I heuristic with a look-ahead and look-back strategy. The third heuristic (ACO III) is a combination of the ACO I heuristic and a SA heuristic for the DFLP.

\subsection{General Nomenclature}

The following nomenclature is used for all the proposed heuristics.

$N=$ Number of departments

$T=$ Number of periods.

$M=$ Number of ants used in the heuristics.

$\pi^{k}=\left(\pi_{1}^{k}, \pi_{2}^{k}, \ldots, \pi_{T}^{k}\right)$, set of permutations, solution or layout plan for ant $k(k=1$, $2, \ldots, M)$

$\pi_{t}^{k}=\left(\pi_{1 t}^{k}, \pi_{t 1}^{k}, \ldots, \pi_{N t}^{k}\right)$, layout for ant $k$ at time period $t$. 
$\pi^{*}=$ Best layout plan or solution (i.e., its objective function value is the minimum of all solutions).

$W=$ Flow matrix which stores the flow of materials between departments.

$D=$ Distance matrix which stores the distances between the locations.

$P=$ Pheromone trail matrix which has $N^{*} N^{*} T$ elements.

$p_{\pi_{i t}, t}=$ Entries of matrix $P$ which measures the desirability of assigning department $\pi_{i t}$ to location $j$ at time period $t$.

$M a=$ Total material handling cost.

$R e=$ Total rearrangement cost.

$I_{\max }=$ Total number of iterations for the ACO heuristics.

$R=$ Number of pheromone trail swaps.

$S=$ Consecutive number of iterations without improvement before diversification.

$q=$ Parameter used to select the pheromone trail swap policy.

$\alpha_{1}=$ Parameter used to control the evaporation of the pheromone trail. A value of $\alpha_{1}$ close to 0 implies that the pheromone trails remain active a long time. Otherwise, a value close to 1 implies a high degree of evaporation and a shorter memory of the system.

$\alpha_{2}=$ Parameter used to enforce certain pheromone trails based on the best- found solution.

$\Delta 1\left(\pi_{i t}, \pi_{j t}, t\right)=$ Change in material handling costs after exchanging the location of departments $\pi_{i t}$ and $\pi_{j t}$ in time period $t$.

$\Delta 2\left(\pi_{i t}, \pi_{j t}, t\right)=$ Change in rearrangement costs after exchanging the location of 
departments $\pi_{i t}$ and $\pi_{j t}$ in time period $t$.

$\Delta\left(\pi_{i t}, \pi_{j t}, t\right)=\Delta 1\left(\pi_{i t}, \pi_{j t}, t\right)+\Delta 2\left(\pi_{i t}, \pi_{j t}, t\right)$, change in the objective function value after exchanging the locations of departments $\pi_{i t}$ and $\pi_{j t}$ in time period $t$.

$f\left(\pi^{k}\right)=$ objective function value (or total cost) of ant $k$.

$f\left(\pi^{*}\right)=$ Best objective function value found previously.

\subsection{ACO I Heuristic}

ACO I heuristic is a modification of the HAS-QAP heuristic for the DFLP. The heuristic simulates the way ants search for food and find their way back to the nest using the shortest path. The layout plan is a series of layouts for each period in the planning horizon. Each period has its own flow data. Therefore, the input data for this heuristic consist of a series of flow data associated with each period, distance matrix (distances between locations), and rearrangement costs.

\subsubsection{Pairwise Exchange Heuristic}

\subsubsection{Concept}

The pairwise exchange heuristic is an important component of the proposed ACO heuristics. For the DFLP, the pairwise exchange heuristic is implemented in three sequential steps:

1. Randomly select a time period $t$. 
2. Randomly select two departments $\left(\pi_{u t}\right.$ and $\left.\pi_{v t}\right)$ for exchange, in period $t$.

3. Consider exchanging the locations of departments $\pi_{u t}$ and $\pi_{v t}$ in time period $t$ by calculating $\Delta\left(\pi_{u t}, \pi_{v t}, t\right)$. If $\Delta\left(\pi_{u t}, \pi_{v t}, t\right)$ is less than zero, accept the exchange. Else, reject the exchange.

The pairwise exchange heuristic presented above is a random descent heuristic, which is repeated for a certain number of iterations. In step 3, the change in total cost, $\Delta\left(\pi_{u t}, \pi_{v t}, t\right)$ is calculated by summing the change in material handling cost, $\Delta 1\left(\pi_{u t}, \pi_{v t}, t\right)$ with the change in rearrangement cost, $\Delta 2\left(\pi_{u t}, \pi_{v t}, t\right)$. Rearrangement costs are incurred when the locations of at least two departments in consecutive time periods are changed. Calculating the change in total cost is further discussed below.

\subsubsection{Heuristic Description}

Generally, the material handling (or flow) cost of a layout plan for ant $k$ is calculated by using the following formula:

$$
\text { Total flow cost for ant } k=\sum_{i=1}^{N} \sum_{j=1}^{N} \sum_{t=1}^{T} d_{i j} *_{\pi_{i t}^{k} \pi_{j t}^{k}}
$$

However, when the distance matrix and flow matrix are symmetric, the above formula can be stated as:

$$
\text { Total flow cost for ant } k=2 * \sum_{i=1}^{N} \sum_{j=i+1}^{N} \sum_{t=1}^{T} d_{i j} *_{w}{ }_{i t}^{k} \pi_{j t}^{k}
$$

This modification will reduce computational time, especially for large size problems. Also, The rearrangement cost is calculated by considering the changes in the locations 
of departments in consecutive time periods. The total cost for ant $k$ is the sum of the total flow cost and rearrangement cost.

For the DFLP, the change in the objective function value, $\Delta\left(\pi_{i t}^{k}, \pi_{j t}^{k}, t\right)$, consists of two parts: the change in material handling cost, $\Delta 1\left(\pi_{i t}^{k}, \pi_{j t}^{k}, t\right)$ and the change in rearrangement cost, $\Delta 2\left(\pi_{i t}^{k}, \pi_{j t}^{k}, t\right)$. Therefore, the change in total cost for ant $k$ is

$$
\Delta\left(\pi_{i t}^{k}, \pi_{j t}^{k}, t\right)=\Delta 1\left(\pi_{i t}^{k}, \pi_{j t}^{k}, t\right)+\Delta 2\left(\pi_{i t}^{k}, \pi_{j t}^{k}, t\right) .
$$

The change in material handling cost is calculated using the following formula:

$$
\begin{aligned}
& \Delta 1\left(\pi_{i t}^{k}, \pi_{j t}^{k}, t\right)=\left(d_{i j}-d_{j i}\right) *\left(w_{\pi_{j i}^{k} \pi_{i t}^{k}}-w_{\pi_{i i}^{k} \pi_{j t}^{k}}\right)+\sum_{s \neq i, j}\left(d_{s i}-d_{s j}\right) *\left(w_{\pi_{s t}^{k} \pi_{j t}^{k}}-w_{\pi_{s t}^{k} \pi_{i t}^{k}}\right) \\
& +\left(d_{i s}-d_{j s}\right) *\left(w_{\pi_{j i}^{k} \pi_{s t}^{k}}-w_{\pi_{i t}^{k} \pi_{s t}^{k}}\right)
\end{aligned}
$$

Change in rearrangement cost, $\Delta 2\left(\pi_{i t}^{k}, \pi_{j t}^{k}, t\right)$, is determined by considering the locations of the pairs of departments which are exchanged in time period $t$ and the locations of these departments in time periods $t-1$ and $t+1$. If the locations of the departments selected for exchange is different in time periods $t$ and $t+1$, then rearrangement costs are incurred. This is illustrated in the example below.

\subsubsection{Illustration of Calculating the change in Total Cost}

Consider an initial layout plan for a DFLP instance with 6 departments and 4 time periods (i.e., $N=6$ and $T=4$ ) in figure 4.1 below. The layout plan assigns departments $6,5,4,3,2$, and 1 to locations $1,2,3,4,5$, and 6 , respectively, in time periods $1,2,3$, and 4 . Rearrangement cost is zero since all the layouts are the same at each time period. In other words, the locations of the departments do not change 
during the planning horizon. Hence, the total cost of the layout plan is the sum of the material handling and rearrangement costs.

$\begin{array}{lllllll}\mathbf{6} & \mathbf{5} & \mathbf{4} & \mathbf{3} & \mathbf{2} & \mathbf{1} & t=1 \\ \mathbf{6} & \mathbf{5} & \mathbf{4} & \mathbf{3} & \mathbf{2} & \mathbf{1} & t=2 \\ \mathbf{6} & \mathbf{5} & \mathbf{4} & \mathbf{3} & \mathbf{2} & \mathbf{1} & t=3 \\ \mathbf{6} & \mathbf{5} & \mathbf{4} & \mathbf{3} & \mathbf{2} & \mathbf{1} & t=4\end{array}$

Figure 4.1: Layout plan for a DFLP instance with $N=6$ and $T=4$.

The next step is to improve the initial layout plan by using the pairwise exchange procedure presented above. If time period 2 is randomly selected and departments 2 and 5 are randomly selected for exchange, see figure 4.2 , department 5 is assigned to location 2 and department 2 is assigned to location 5. The change in total costs, $\Delta\left(\pi_{u t}, \pi_{v t}, t\right)$ is calculated using formula (3) where $\pi_{u t}=5, \pi_{v t}=2$, and $t=2$ (i.e., calculate $\Delta(5,2,2))$. First the change in material handling cost, $\Delta 1(5,2,2)$, is calculated using formula (4). Next, the change in rearrangement cost, $\Delta 2(5,2,2)$, is calculated since the layout at time period 2 is different from the layouts in time periods 1 and 3 . See figure 4.3 for the layout after one iteration of the pairwise exchange procedure.

\section{$6 \quad 5 \quad 4 \quad 3 \quad 2 \quad 1 \quad t=2$}

Figure 4.2: Time period and departments selected for exchange. 


$$
\begin{array}{lllllll}
\mathbf{6} & \mathbf{5} & \mathbf{4} & \mathbf{3} & \mathbf{2} & \mathbf{1} & t=1 \\
\mathbf{6} & \mathbf{2} & \mathbf{4} & \mathbf{3} & \mathbf{5} & \mathbf{1} & t=2 \\
\mathbf{6} & \mathbf{5} & \mathbf{4} & \mathbf{3} & \mathbf{2} & \mathbf{1} & t=3 \\
\mathbf{6} & \mathbf{5} & \mathbf{4} & \mathbf{3} & \mathbf{2} & \mathbf{1} & t=4
\end{array}
$$

Figure 4.3: The layout plan after pairwise exchange.

When calculating the rearrangement cost, $\Delta 2(5,2,2)$, the locations of the pair of departments which were exchanged in time period 2 (i.e., $\pi_{u t}=5$ and $\pi_{v t}=2$ ) and the locations of these departments in time periods $t-1=1$ and $t+1=3$ are considered. Since the locations of departments 2 and 5 is different in time periods 1 and 3 , and the cost of moving a department is 1,000 , then the change in rearrangement costs is 4,000 .

\subsubsection{ACO I Heuristic Description}

Step 1: Generate initial solution for each ant.

In this step, the initial solutions (i.e., $\pi^{1}, \pi^{2}, \ldots, \pi^{m}$ ) are generated. First, for each ant, a permutation (or layout) for the first time period is generated. Then this layout is used for all the remaining layouts for time periods 2 , $3, \ldots, T$. Thus, the layouts for all time periods are the same for each ant. Therefore, the rearrangement cost is zero. In the proposed heuristics, the initial layout is generated as follows. For ant $k$, the initial layout is generated by assigning departments $k, k+1, \ldots, N, 1,2, \ldots, k$-1 to locations $1,2, \ldots, N$, respectively. Then, this layout is used for subsequent periods.

For instance, for ant 1 , the solution is generated such that departments 1 , 
$2, \ldots, N$ are assigned to locations $1,2, \ldots, N$, respectively, as defined below.

$\begin{array}{lllllll}\mathbf{1} & \mathbf{2} & \mathbf{3} & \mathbf{4} & \mathbf{5} & \mathbf{6} & t=1 \\ \mathbf{1} & \mathbf{2} & \mathbf{3} & \mathbf{4} & \mathbf{5} & \mathbf{6} & t=2 \\ \mathbf{1} & \mathbf{2} & \mathbf{3} & \mathbf{4} & \mathbf{5} & \mathbf{6} & t=3 \\ \mathbf{1} & \mathbf{2} & \mathbf{3} & \mathbf{4} & \mathbf{5} & \mathbf{6} & t=4\end{array}$

For ant 2, the solution is generated such that departments $2,3, \ldots, N, 1$ are assigned to locations $1,2, \ldots, \mathrm{N}$, respectively, as defined below.

$\begin{array}{lllllll}\mathbf{2} & \mathbf{3} & \mathbf{4} & \mathbf{5} & \mathbf{6} & \mathbf{1} & t=1 \\ \mathbf{2} & \mathbf{3} & \mathbf{4} & \mathbf{5} & \mathbf{6} & \mathbf{1} & t=2 \\ \mathbf{2} & \mathbf{3} & \mathbf{4} & \mathbf{5} & \mathbf{6} & \mathbf{1} & t=3 \\ \mathbf{2} & \mathbf{3} & \mathbf{4} & \mathbf{5} & \mathbf{6} & \mathbf{1} & t=4\end{array}$

Step 2: Use pairwise exchange heuristic to improve the solution or layout plan for each ant and let $\pi^{*}$ represent the best solution.

The purpose of this step is to improve the initial solutions and use the best solution $\pi^{*}$ to initialize the pheromone trail matrix in step 3. This step is repeated for $N^{*} N^{*} T$ iterations.

Step 3: Pheromone trail matrix initialization.

The pheromone trail is the most important component in the ACO heuristics. The pheromone trail matrix, $P$, allows the heuristic to accept uphill moves (i.e., non-improving solutions) so that the heuristic does not converge to a poor local optimum. Entries of matrix $P, p_{\pi_{i t} j t}$, measures the desirability of assigning department $\pi_{i t}$ to location $j$ at time period $t$. Initially, all the 
entries of $P$ are set to $1 / Q f\left(\pi^{*}\right)$ where $Q$ is a heuristic parameter.

Step 4: Start main loop.

Initialize and define additional heuristic parameters. Define $I_{\max }$, which represents the total number of iterations performed and initialize all other parameters (i.e., $R, S, q, \alpha_{1}$ and $\alpha_{2}$ ). Therefore, the stopping criterion is to terminate the heuristic after $I_{\max }$ iterations have been performed.

Step 5: Perform $R$ pheromone trail swaps.

In this step, a new solution $\hat{\pi}^{1}, \hat{\pi}^{2}, \ldots, \hat{\pi}^{m}$ is generated for each ant by considering $R$ pheromone trail swaps. First, a time period is selected randomly. In this time period, two department locations are selected for exchange. First, department $\pi_{u t}^{k}$ is selected randomly between 1 and $N$. Then, a location $v \neq u$ is selected using one of the two policies presented below. The first policy is selected with a probability $q$.

1) Select $v$ such that $p_{\pi_{u t}^{k}, v, t}+p_{\pi_{v t}^{k}, u, t}$ is maximized. This policy exploits the pheromone trail.

2) Select $v$ with probability:

$$
\frac{p_{\pi_{u t}^{k}, v, t}+p_{\pi_{v t}^{k}, u, t}}{\sum_{j \neq u}\left(p_{\pi_{u t}^{k}, j, t}+p_{\pi_{j t}^{k}, u, t}\right)} \text {. This policy explores the solution space. }
$$

However, at the first iteration (also after implementing the diversification strategy), departments $u$ and $v$ are randomly selected, since all the entries in the pheromone trail matrix are the same.

Step 6: Use the pairwise exchange heuristic to improve the solutions. 
The solutions $\hat{\pi}^{1}, \hat{\pi}^{2}, \mathrm{~K}, \hat{\pi}^{m}$ are improved using the pairwise exchange heuristic. The improved solutions are denoted as $\pi^{1}, \pi^{2}, \mathrm{~K}, \pi^{m}$. This step is repeated for $N^{*} N^{*} T$ iterations.

Step 7: Perform intensification strategy.

This step is used to explore the neighborhood of good solutions more thoroughly. At the start of the heuristic and if the best solution has improved, the intensification process will be activated. When intensification is active, each ant $k$ starts its next iteration with the best set of permutations between the solutions $\pi^{k}$ and $\pi^{k}$. In contrast, if the best solution has not improved, the intensification strategy will not be activated and each ant starts its next iteration with the solutions $\pi^{k}$. The intensification strategy remains active while at least one ant improves its solution during an iteration.

Step 8: Update pheromone trail matrix.

To speed-up the convergence of the heuristic, the pheromone trail matrix is updated using only the best solution obtained thus far, as in Dorigo (1999). First, all the pheromone trails are weakened (evaporated) by setting: $p_{\pi_{i t} j t}=\left(1-\alpha_{1}\right) * p_{\pi_{i t} j t}$ where $0<\alpha_{1}<1$ is a parameter that controls the evaporation of pheromone trails. A value of $\alpha_{1}$ close to 0 implies that the pheromone trails remain active a long time, while a value close to 1 implies a high degree of evaporation and a shorter memory of the system. Then, the pheromone trails contained in the best solution $\pi *$ are reinforced by setting: 
$p_{\pi_{i t}^{*}, i, t}=p_{\pi_{i t}^{*}, i, t}+\alpha_{2} / f\left(\pi^{*}\right)$, where $\alpha_{2}$ is a parameter that controls the

reinforcement of the pheromone trails.

Step 9: Perform diversification strategy.

The diversification mechanism is activated after $S$ consecutive iterations without improvement to the best solution obtained. Once this mechanism is activated, all of the information (e.g., solutions, trail matrix) is erased and the heuristic is started from the beginning where only the best solution obtained from an ant is used in the next iteration. The other $M-1$ initial solutions are generated randomly. The only other information that is used is the iteration number. Therefore, the heuristic is repeated for $I_{\max }$ - iteration number. Go to step 5.

\subsubsection{Illustration of the ACO I Heuristic}

Consider a DFLP instance with 6 departments and 2 time periods (i.e., $N=6, T=$

2) where rearrangement cost for each department is 1000 . The material flow matrix $(W)$ is given in figure 4.4 , and the layout configuration is a $2 \times 3$ layout which is shown in figure 4.5. In figure 4.6, the distance matrix $(D)$ is given. 


\begin{tabular}{|r|r|r|r|r|r||}
\hline 0 & 90 & 689 & 194 & 165 & 494 \\
\hline 668 & 0 & 1324 & 811 & 241 & 206 \\
\hline 631 & 387 & 0 & 125 & 281 & 375 \\
\hline 80 & 495 & 615 & 0 & 222 & 221 \\
\hline 276 & 204 & 1127 & 490 & 0 & 676 \\
\hline 109 & 409 & 1780 & 394 & 200 & 0 \\
\hline \hline 0 & 257 & 1632 & 330 & 117 & 285 \\
\hline 159 & 0 & 1309 & 297 & 803 & 404 \\
\hline 98 & 82 & 0 & 271 & 222 & 383 \\
\hline 110 & 404 & 1174 & 0 & 750 & 386 \\
\hline 73 & 507 & 1679 & 190 & 0 & 107 \\
\hline 152 & 487 & 355 & 646 & 315 & 0 \\
\hline \hline
\end{tabular}

Figure 4.4: Material flow matrix for the DFLP instance.

\begin{tabular}{|l|l|l|}
\hline 1 & 2 & 3 \\
\hline 4 & 5 & 6 \\
\hline
\end{tabular}

Figure 4.5: Layout configuration for the DFLP instance.

\begin{tabular}{|r|r|r|r|r|r|}
\hline 0 & 1 & 2 & 1 & 2 & 3 \\
\hline 1 & 0 & 1 & 2 & 1 & 2 \\
\hline 2 & 1 & 0 & 3 & 2 & 1 \\
\hline 1 & 2 & 3 & 0 & 1 & 2 \\
\hline 2 & 1 & 2 & 1 & 0 & 1 \\
\hline 3 & 2 & 1 & 2 & 1 & 0 \\
\hline
\end{tabular}

Figure 4.6: Distance matrix for the DFLP instance. 
Parameters setting for the DFLP instance:

$\checkmark \quad$ Number of ants, $M=2$;

$\checkmark \quad$ Number of Iterations, $\operatorname{Imax}=2$;

$\checkmark$ Pheromone trail initialization parameter, $Q=10^{-8}$;

$\checkmark \quad$ Parameter to decide which swap policy to use, $q=0.9$;

$\checkmark \quad$ Number of pheromone trail swaps, $R=1$;

$\checkmark \quad$ Pheromone trail evaporation parameter, $\alpha_{1}=0.1$;

$\checkmark$ Pheromone trail intensification parameter, $\alpha_{2}=10^{7}$.

Step 1: Generate initial solutions $\pi^{1}$ and $\pi^{2}$.
For ant $1, \pi^{l}=$
For ant $2, \pi^{2}=$
$f\left(\pi^{l}\right)=46,563$
$f\left(\pi^{2}\right)=45,765$

Note layouts for each time period are the same for both ants. Therefore, rearrangement costs are zero for both ants. However, ant 2 gives the best solution.

Step 2: Use pairwise exchange heuristic to improve initial solutions. After 72 iterations $\left(N^{*} N^{*} T=(6)(6)(2)=72\right)$, the following solutions were obtained where $f\left(\pi^{*}\right)$ $=44,302$.

For ant $1, \pi^{1}=$

231456

132456

$f\left(\pi^{l}\right)=44,302$
For ant 2: $\pi^{2}=$

234561

234561

$f\left(\pi^{2}\right)=45,765$ 
Step 3: Initialize the pheromone trail matrix $P$. By using the formula $p_{\pi_{i t} j t}=1 / Q f\left(\pi^{*}\right)$, all the entries are equal to 2,257 .

Step 4: Begin main loop.

Initialize parameters: $I_{\max }=2, q=0.9, R=1, \alpha_{1}=0.1$, and $\alpha_{2}=10^{7}$.

\section{$\underline{1^{\text {st }} \text { Iteration: }}$}

Step 5: Perform pheromone trail swap.

At the first iteration, step 5 performs a random swap instead of using the trail matrix to perform a pheromone tail swap, since the values of the entries in the pheromone trail matrix are all equal. Using the solution for ant 1 in Step 1, randomly generate a number $t$ (either 1 or 2), say for instance $t=1$. Next, a department $\pi_{u 1}^{1}$ is randomly selected, say $\pi_{u 1}^{1}=4(u=4)$. Then, randomly generate another department $\pi_{v 1}^{1}=5(v=5)$. The locations of these departments are exchanged. The same procedure is applied to ant 2 , and the following layout plans are obtained.

$$
\begin{array}{rr}
\text { For ant } 1, \hat{\pi}^{1}= & \text { For ant } 2, \hat{\pi}^{2}= \\
123546 & 134562 \\
123456 & 234561 \\
f\left(\hat{\pi}^{1}\right)=48,464 & f\left(\hat{\pi}^{2}\right)=47,116
\end{array}
$$

Step 6: Use the pairwise exchange heuristic to improve the solutions $\hat{\pi}^{1}, \hat{\pi}^{2}$. The following solutions are produced.
For ant $1, \pi^{1}=$
For ant $2, \pi^{2}=$ 


$$
f\left(\pi^{1}\right)=44,439 \quad f\left(\pi^{2}\right)=43,767
$$

Therefore, the best solution found is improved (i.e., $f\left(\pi^{*}\right)=43,767$ ).

Step 7: Perform intensification strategy.

Since the intensification strategy is active at the start of the heuristic, the best solution between $\pi^{k}$ and $\pi^{k}$ is used as the starting solution for the next iteration. According to the objective function values for ant $1, f\left(\pi^{l}\right)=46,563$ and $f\left(\pi^{1}\right)=$ $44,439, \quad \pi^{1}$ is the best solution. According to the objective function values for ant 2 , $f\left(\pi^{2}\right)=45,765$ and $f\left(\pi^{2}\right)=43,767, \pi^{2}$ is the best solution. Therefore, solutions $\pi^{1}$ and $\pi^{2}$ are the starting solutions for ants 1 and 2 , respectively, at the next iteration.

Step 8: Update the pheromone trail matrix.

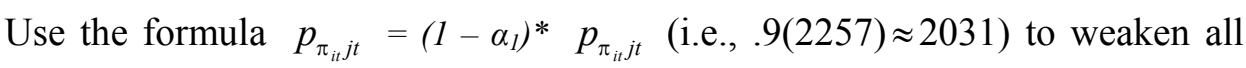
pheromone trials (i.e., all entries in matrix $P$ ). Use the best solution found thus far (i.e., $\left.f\left(\pi^{*}\right)=43,767\right)$, and the formula $p_{\pi_{i t}^{*}, i, t}=p_{\pi_{i t, i, t}^{*}}+\alpha_{2} / f\left(\pi^{*}\right)\left(\right.$ i.e., $2031+10^{7} / 43,767$ $\approx 2259)$ to intensify pheromone trials which appear in the best solution $\pi^{*}$. The updated pheromone trail matrix $P$ is given below. 


\begin{tabular}{|l|l|l|l|l|l||}
\hline \hline 2259 & 2031 & 2031 & 2031 & 2031 & 2031 \\
\hline 2031 & 2031 & 2259 & 2031 & 2031 & 2031 \\
\hline 2031 & 2259 & 2031 & 2031 & 2031 & 2031 \\
\hline 2031 & 2031 & 2031 & 2031 & 2031 & 2259 \\
\hline 2031 & 2031 & 2031 & 2259 & 2031 & 2031 \\
\hline 2031 & 2031 & 2031 & 2031 & 2259 & 2031 \\
\hline \hline 2259 & 2031 & 2031 & 2031 & 2031 & 2031 \\
\hline 2031 & 2031 & 2259 & 2031 & 2031 & 2031 \\
\hline 2031 & 2259 & 2031 & 2031 & 2031 & 2031 \\
\hline 2031 & 2031 & 2031 & 2031 & 2031 & 2259 \\
\hline 2031 & 2031 & 2031 & 2259 & 2031 & 2031 \\
\hline 2031 & 2031 & 2031 & 2031 & 2259 & 2031 \\
\hline
\end{tabular}

\section{$\underline{2^{\text {st }} \text { Iteration: }}$}

Step 5: Perform pheromone trail swaps.

For ant 1 , randomly generate a number $t$ (either 1 or 2 ), say for instance $t=1$.

Next, a department $\pi_{u 1}^{1}$ is randomly selected, say $\pi_{u 1}^{1}=4(u=3)$. Then, randomly generate a number, say 0.3. Since $0.3<q=0.9$, use the first swap policy to select location $v$. Therefore, $v=6$ is selected since $p_{4,6,1}+p_{5,3,1}=2259+2031$ is the maximum. The same procedure is applied to ant 2 , and the following layouts are obtained.
For ant $1, \hat{\pi}^{1}=$
For ant $2, \hat{\pi}^{2}=$

125634

123645

$$
f\left(\hat{\pi}^{1}\right)=47,062
$$

\section{4}

$$
f\left(\hat{\pi}^{2}\right)=43,991
$$

Step 6: Use the pairwise exchange heuristic to improve the solutions $\hat{\pi}^{1}, \hat{\pi}^{2}$. The following solutions are produced. 
For ant $1, \pi^{1}=$

154632

135642
For ant $2, \pi^{2}=$

132564

132564

$$
f\left(\pi^{2}\right)=43,767
$$

Therefore, the best solution found is $\operatorname{still} f\left(\pi^{*}\right)=43,767$.

Step 7: Perform intensification strategy.

According to the objective function values for ant $1, f\left(\pi^{1}\right)=44,439$ and $f\left({ }^{1} \pi^{1}\right)$ $=44,245, \pi^{1}$ is the best solution. According to the objective function values for ant 2, $f\left(\pi^{2}\right)=43,767$ and $f\left(\pi^{2}\right)=43,767, \quad \pi^{2}$ is the best solution. Therefore, $\pi^{1}$ and $\pi^{2}$ are the starting solutions for ants 1 and 2, respectively, at $3^{\text {rd }}$ iteration.

Step 8: Update the pheromone trail matrix.

Use the formula $p_{\pi_{i t} j t}=\left(1-\alpha_{1}\right)^{*} p_{\pi_{i t} j t}$ to weaken all pheromone trials (i.e., all entries in matrix $P$ ). Use the best solution found thus far (i.e., $f\left(\pi^{*}\right)=43,767$ ), and the formula $p_{\pi_{i t}^{*}, i, t}=p_{\pi_{i t}^{*}, i, t}+\alpha_{2} / f\left(\pi^{*}\right)$ to intensify pheromone trials which appear in the best solution $\pi^{*}$. The updated pheromone trail matrix $P$ is given below.

\begin{tabular}{|l|l|l|l|l|l||}
\hline \hline 2261 & 1828 & 1828 & 1828 & 1828 & 1828 \\
\hline 1828 & 1828 & 2261 & 1828 & 1828 & 1828 \\
\hline 1828 & 2261 & 1828 & 1828 & 1828 & 1828 \\
\hline 1828 & 1828 & 1828 & 1828 & 1828 & 2261 \\
\hline 1828 & 1828 & 1828 & 2261 & 1828 & 1828 \\
\hline 1828 & 1828 & 1828 & 1828 & 2261 & 1828 \\
\hline \hline 2261 & 1828 & 1828 & 1828 & 1828 & 1828 \\
\hline 1828 & 1828 & 2261 & 1828 & 1828 & 1828 \\
\hline 1828 & 2261 & 1828 & 1828 & 1828 & 1828 \\
\hline 1828 & 1828 & 1828 & 1828 & 1828 & 2261 \\
\hline 1828 & 1828 & 1828 & 2261 & 1828 & 1828 \\
\hline 1828 & 1828 & 1828 & 1828 & 2261 & 1828 \\
\hline
\end{tabular}




\subsection{ACO II Heuristic}

The difference between the ACO I and ACO II heuristics is that the pairwise exchange heuristic in ACO II has a look-ahead and look-back mechanism. In the ACO I heuristic, after a time period is selected and the locations of two departments are exchanged, the change in total cost, $\Delta\left(\pi_{u t}, \pi_{v t}, t\right)$ is used to determine whether to accept or reject this exchange. This exchange only affects the layout of the time period selected for the exchange. However, in the ACO II heuristic, an exchange in the selected time period affects the layout in that period and may affect the layouts of other time periods. This will be illustrated using the DFLP instance in figure 4.7. The look-ahead/look-back pairwise exchange heuristic for the ACO II heuristic is given in figure 4.8. The heuristic is repeated $N^{*} N^{*} T$ times and is performed for each ant.

$\begin{array}{lllllll}\mathbf{6} & \mathbf{5} & \mathbf{4} & \mathbf{3} & \mathbf{2} & \mathbf{1} & t=1 \\ \mathbf{6} & \mathbf{5} & \mathbf{4} & \mathbf{3} & \mathbf{2} & \mathbf{1} & t=2 \\ \mathbf{6} & \mathbf{5} & \mathbf{4} & \mathbf{3} & \mathbf{2} & \mathbf{1} & t=3 \\ \mathbf{6} & \mathbf{5} & \mathbf{4} & \mathbf{3} & \mathbf{2} & \mathbf{1} & t=4\end{array}$

Figure 4.7: The layout plan for the DFLP instance.

Step 1: First, the pairwise exchange heuristic for the ACO I heuristic is performed. If time period 3, location 2, and location 5 (department 5 and department 2, respectively) are randomly selected, then $\Delta(5,2,3)$ is calculated. If this value is greater than zero, then exchanging the locations of departments 2 and 5 will increase total cost. Therefore, the exchange is rejected. However, if this value is less than zero, go to step 2 . 


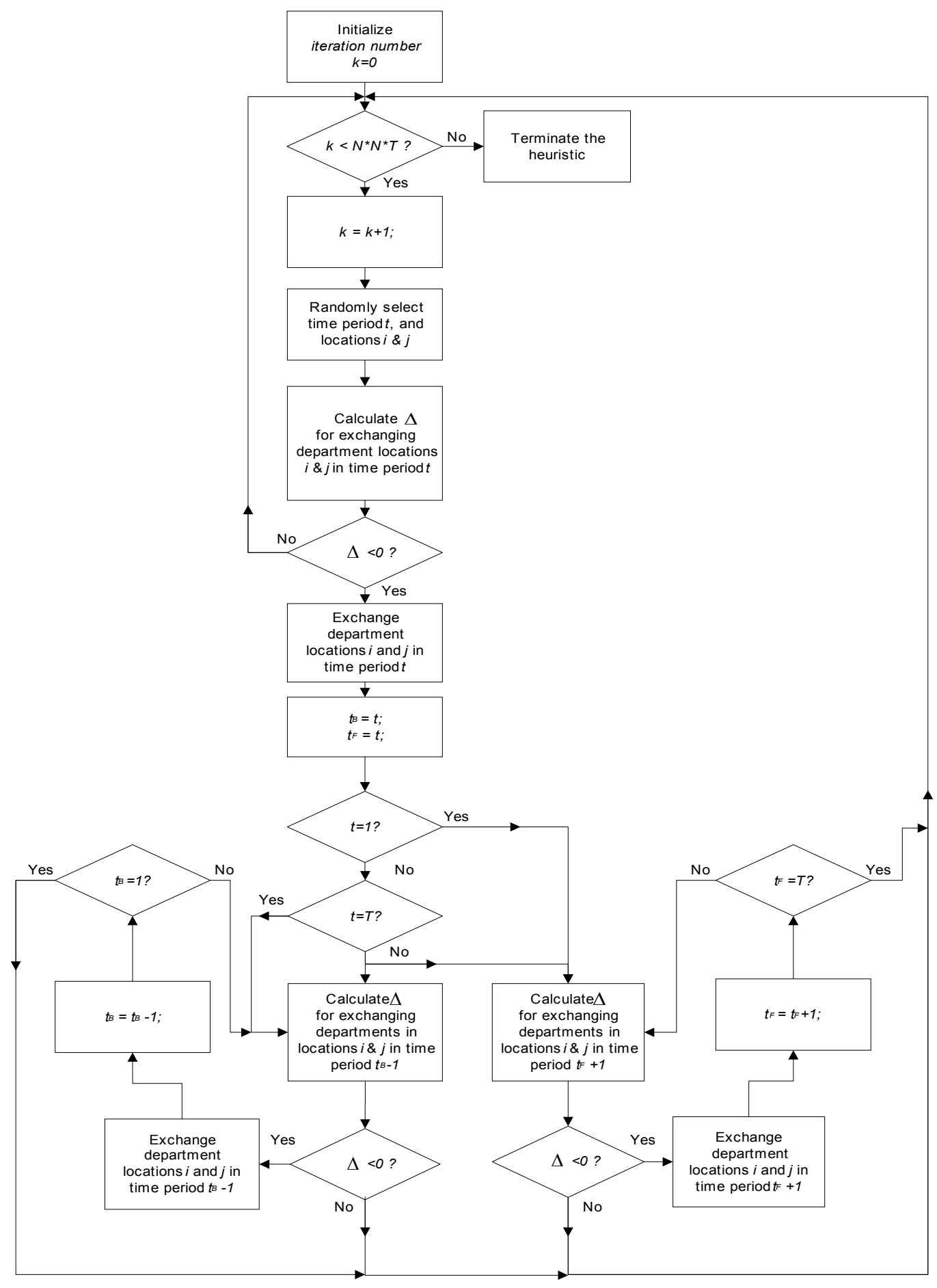

Figure 4.8: Diagram of the look-ahead/look-back exchange procedure. 
Step 2: If exchanging the locations of departments 2 and 5 at time period 3 is accepted in step 1, then the heuristic will look-ahead and look-back ( $t=2$ and 4$)$ to determine if the departments 2 and 5 should be exchanged in the preceding or following periods (see figure 4.9). The departments are exchanged if and only if the exchanges reduce the change in total cost (i.e., exchange the locations of departments 2 and 5 in period 2 if $\Delta(5,2,2)$ is less than zero and exchange the locations of departments 2 and 5 in period 4 if $\Delta(5,2,4)$ is less than zero). If the exchange in period 2 is accepted, then exchanging departments 2 and 5 in period 1 is considered. When an exchange is not accepted in both a preceding or following period, then start the next iteration.

$\begin{array}{lllllll}\mathbf{6} & \mathbf{5} & \mathbf{4} & \mathbf{3} & \mathbf{2} & \mathbf{1} & t=1 \\ \mathbf{6} & \underline{\mathbf{5}} & \mathbf{4} & \mathbf{3} & \underline{\mathbf{2}} & \mathbf{1} & t=2 \\ \mathbf{6} & \mathbf{2} & \mathbf{4} & \mathbf{3} & \mathbf{5} & \mathbf{1} & t=3 \\ \mathbf{6} & \underline{\mathbf{5}} & \mathbf{4} & \mathbf{3} & \underline{\mathbf{2}} & \mathbf{1} & t=4\end{array}$

Figure 4.9: The layout plan after the first exchange.

\subsection{ACO III Heuristic}

The ACO III heuristic combines the ACO I heuristic with a SA heuristic. This heuristic is different from the ACO I heuristic since a SA heuristic is used in place of the pairwise exchange heuristic. See figure 4.10 for the SA heuristic. In this heuristic, the SA parameter $H=a * S$, where $S$ is a heuristic parameter such that a $>0$ and integer. The formula $\exp (-\Delta / H)>\operatorname{rand}(0,1)$ is used to allow "uphill moves" (non-improving 
solutions) so that the heuristic does not converge to a poor local optimum. At the beginning $H$ is a relatively large number, which allows for accepting non-improving exchanges. As $H$ decreases, the probability of accepting non-improving moves decreases. The heuristic is repeated $N^{*} N^{*} T$ times for each ant.

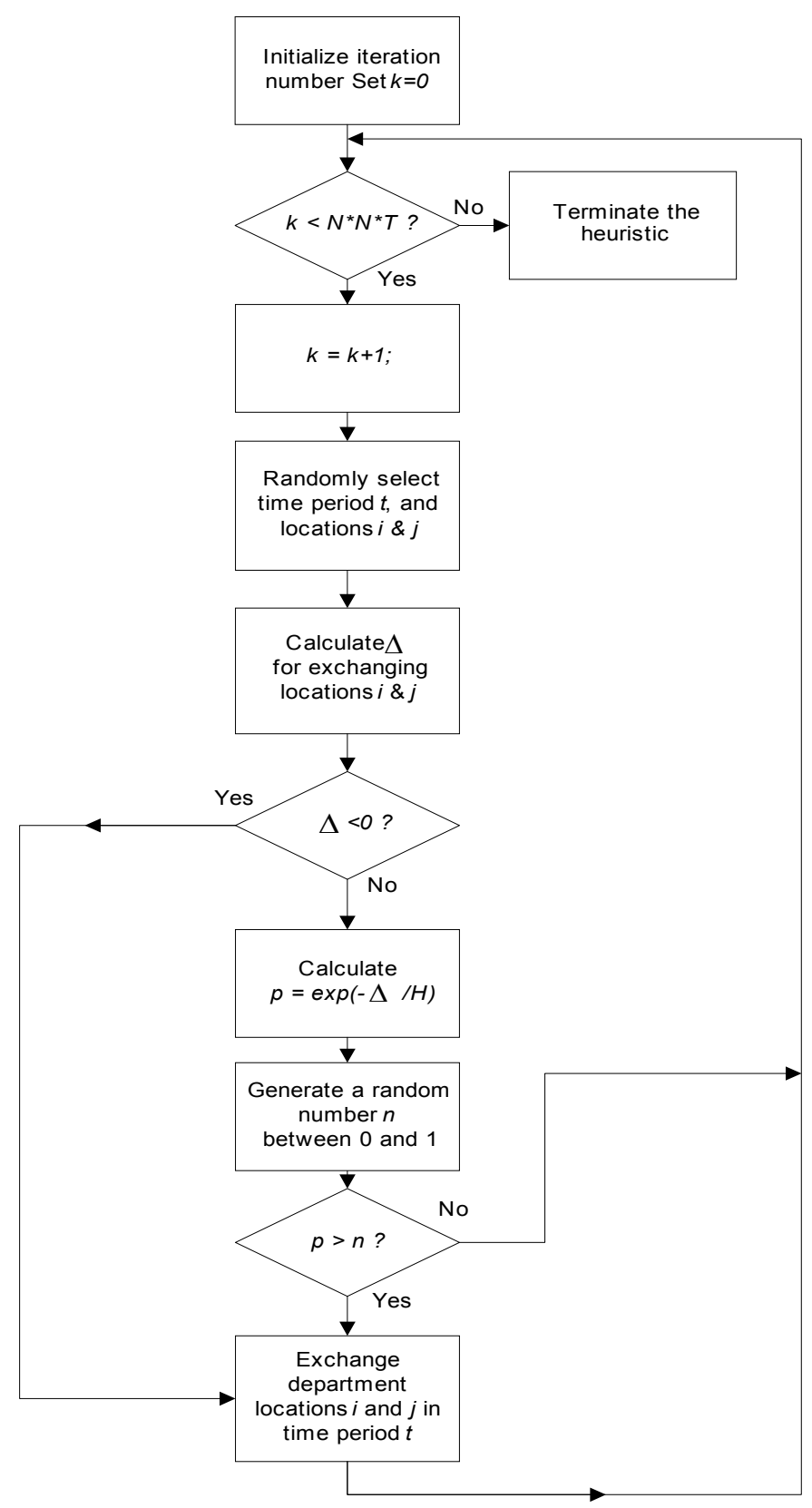

Figure 4.10: Diagram of the SA heuristic. 


\section{CHAPTER 5}

\section{COMPUTATIONAL EXPERIMENTS AND RESULTS}

\subsection{Data Sets}

In this research, two data sets were used to test the proposed ACO heuristics. The first data set was provided by Lacksonen and Enscore (1993). This data set was constructed based on several factors: percentage of new departments/period, number of departments, number of time periods, ratio of rearrangement cost to flow cost (rearrangement/flow cost), percentage of positive flow, and maximum value of flow changes per period. In this data set, the rearrangement cost is the same for all departments and is constant across all periods. Additionally, when new departments replace old departments, the replacement costs are considered, and the cost of replacing a department is equal to the rearrangement cost. This data set includes DFLP instances involving 6,12, 20, and 30 departments (i.e., $N=6,12,20$, and 30), with 3 and 5 periods (i.e., $T=3$ and 5). Each problem with department size $N$ has four 3-period problem instances and four 5-period problem instances. Thus, 32 problem instances are available in this data set.

The second data set was obtained from Balakrishnan and Cheng (2000). Balakrishnan and Cheng recently used this data set to test their GA. Baykasoglu and Gindy (2001) also used this data set to test their SA heuristic. The data set contains problems for 6,15 , and 30 departments (i.e., $N=6,15$, and 30), with 5 and 10 periods, (i.e., $T=5$ and 10). Each problem has 8 instances. Hence, 48 problems are included in 
this data set.

\subsection{ACO Heuristics}

The proposed heuristics ACO I, ACO II and ACO III were applied to these two data sets. All the proposed heuristics have the same initial solutions and the same stopping criterion (i.e., maximum number of iterations is $I_{\max }$ ). All the heuristics were coded in $\mathrm{C}++$ programming language. However, since the proposed $\mathrm{ACO}$ heuristics need to store a lot of information during computation, these $\mathrm{C}++$ codes were run on the $\mathrm{C}++$ Builder (6.0) platform to overcome the size limitation of the complier based on the DOS environment. All the programs were solved on a Pentium III $750 \mathrm{Mhz}$ PC with $512 \mathrm{M}$ of memory.

\subsection{Parameter Settings}

The main parameters are $I_{\max }$ (maximum number of iterations), $R=N^{*} T$ (number of pheromone trail swaps), $\alpha_{1}$ (the parameter controlling the evaporation of the pheromone trails), $\alpha_{2}$ (the parameter used to enforce certain pheromone trails), $Q$ (the parameter used to initialize the pheromone trail matrix), $q$ (percent use for determining the pheromone trail swap policy), $S=R / 2$ (maximum number of consecutive iterations without improvement before diversification), and $M$ (number of ants used in heuristic). The parameter settings for data set 1 and data set 2 are given in tables 5.1 and 5.2, respectively. 


\begin{tabular}{|c|c|c|c|c|c|c|c|c|}
\hline \multicolumn{2}{|c|}{ For data set 1} & \multirow[b]{2}{*}{ Parameters } & \multirow{2}{*}{\multicolumn{2}{|c|}{ ACO I }} & \multirow{2}{*}{\multicolumn{2}{|c|}{ ACO II }} & \multirow{2}{*}{\multicolumn{2}{|c|}{ ACO III }} \\
\hline No. of & No. of & & & & & & & \\
\hline \multirow{6}{*}{6} & \multirow{3}{*}{3} & $M \quad I_{\max }$ & 10 & 1000 & 10 & 1000 & 10 & 1000 \\
\hline & & $\alpha_{1} \quad \alpha_{2}$ & 0.2 & $10^{7}$ & 0.2 & $10^{7}$ & 0.2 & $10^{7}$ \\
\hline & & $q \quad Q$ & 8 & $10^{-8}$ & 8 & $10^{-8}$ & 8 & $10^{-8}$ \\
\hline & \multirow{3}{*}{5} & $M \quad I_{\max }$ & 15 & 1500 & 15 & 1500 & 15 & 1500 \\
\hline & & $\alpha_{1} \quad \alpha_{2}$ & 0.2 & $2 \times 10^{7}$ & 0.2 & $2 \times 10^{7}$ & 0.2 & $2 \times 10^{7}$ \\
\hline & & $q$ & 8 & $10^{-8}$ & 8 & $10^{-8}$ & 8 & $10^{-8}$ \\
\hline \multirow{6}{*}{12} & \multirow{3}{*}{3} & $M \quad \max$ & 20 & 2000 & 20 & 2000 & 20 & 2000 \\
\hline & & $\alpha_{1}$ & 0.2 & $2 \times 10^{7}$ & 0.2 & $2 \times 10^{7}$ & 0.2 & $2 \times 10^{7}$ \\
\hline & & $q \quad Q$ & 8 & $10^{-8}$ & 8 & $10^{-8}$ & 8 & $10^{-8}$ \\
\hline & \multirow{3}{*}{5} & $M \quad I_{\max }$ & 25 & 2500 & 20 & 2500 & 20 & 2500 \\
\hline & & $\alpha_{1}$ & 0.2 & $2 \times 10^{7}$ & 0.2 & $2 \times 10^{7}$ & 0.2 & $2 \times 10^{7}$ \\
\hline & & $q$ & 8 & $10^{-8}$ & 8 & $10^{-8}$ & 8 & $10^{-8}$ \\
\hline \multirow{6}{*}{20} & \multirow{3}{*}{3} & $M \quad \max$ & 30 & 3000 & 30 & 3000 & 30 & 3000 \\
\hline & & $\alpha_{1}$ & 0.3 & $3.5 \times 10^{6}$ & 0.3 & $3.5 \times 10^{6}$ & 0.3 & $3.5 \times 10^{6}$ \\
\hline & & $q$ & 7 & $10^{-8}$ & 7 & $10^{-8}$ & 7 & $10^{-8}$ \\
\hline & \multirow{3}{*}{5} & $M$ & 35 & 3500 & 35 & 3500 & 35 & 3500 \\
\hline & & $\alpha_{1}$ & 0.3 & $3.5 \times 10^{6}$ & 0.3 & $3.5 \times 10^{6}$ & 0.3 & $3.5 \times 10^{6}$ \\
\hline & & $q \quad Q$ & 7 & $10^{-8}$ & 7 & $10^{-8}$ & 7 & $10^{-8}$ \\
\hline \multirow{6}{*}{30} & \multirow{3}{*}{3} & $M \quad I_{\max }$ & 40 & 4000 & 40 & 4000 & 40 & 4000 \\
\hline & & $\alpha_{1} \quad \alpha_{2}$ & 0.3 & $3 \times 10^{6}$ & 0.3 & $3 \times 10^{6}$ & 0.3 & $3 \times 10^{6}$ \\
\hline & & $q \quad Q$ & 7 & $10^{-8}$ & 7 & $10^{-8}$ & 7 & $10^{-8}$ \\
\hline & \multirow{3}{*}{5} & $M \quad I_{\max }$ & 45 & 5000 & 45 & 5000 & 45 & 5000 \\
\hline & & $\alpha_{1}$ & 0.3 & $3 \times 10^{6}$ & 0.3 & $3 \times 10^{6}$ & 0.3 & $3 \times 10^{6}$ \\
\hline & & $q$ & 7 & $10^{-8}$ & 7 & $10^{-8}$ & 7 & $10^{-8}$ \\
\hline
\end{tabular}

Table 5.1: Parameter settings for data set 1 . 


\begin{tabular}{|c|c|c|c|c|c|c|c|c|}
\hline \multicolumn{2}{|c|}{ For data set 2} & \multirow[b]{2}{*}{ Parameters } & \multirow{2}{*}{\multicolumn{2}{|c|}{ ACO I }} & \multirow{2}{*}{\multicolumn{2}{|c|}{ ACO II }} & \multirow{2}{*}{\multicolumn{2}{|c|}{ ACO III }} \\
\hline No. of & No. of time & & & & & & & \\
\hline \multirow{6}{*}{6} & \multirow{3}{*}{5} & $M \quad I_{\max }$ & 15 & 1500 & 15 & 1500 & 15 & 1500 \\
\hline & & $\alpha_{1} \quad \alpha_{2}$ & 0.2 & $2 \times 10^{7}$ & 0.2 & $2 \times 10^{7}$ & 0.2 & $2 \times 10^{7}$ \\
\hline & & $q \quad Q$ & 8 & $10^{-8}$ & 8 & $10^{-8}$ & 8 & $10^{-8}$ \\
\hline & \multirow{3}{*}{10} & $M \quad I_{\max }$ & 20 & 2000 & 20 & 2000 & 20 & 2000 \\
\hline & & $\alpha_{1} \quad \alpha_{2}$ & 0.2 & $2 \times 10^{7}$ & 0.2 & $2 \times 10^{7}$ & 0.2 & $2 \times 10^{7}$ \\
\hline & & $q \quad Q$ & 8 & $10^{-8}$ & 8 & $10^{-8}$ & 8 & $10^{-8}$ \\
\hline \multirow{6}{*}{15} & \multirow{3}{*}{5} & $M \quad I_{\max }$ & 25 & 2500 & 20 & 2500 & 20 & 2500 \\
\hline & & $\alpha_{1} \quad \alpha_{2}$ & 0.2 & $2 \times 10^{7}$ & 0.2 & $2 \times 10^{7}$ & 0.2 & $2 \times 10^{7}$ \\
\hline & & $q \quad Q$ & 8 & $10^{-8}$ & 8 & $10^{-8}$ & 8 & $10^{-8}$ \\
\hline & \multirow{3}{*}{10} & $M \quad I_{\max }$ & 30 & 3000 & 30 & 3000 & 30 & 3000 \\
\hline & & $\alpha_{1} \quad \alpha_{2}$ & 0.3 & $3.5 \times 10^{6}$ & 0.3 & $3.5 \times 10^{6}$ & 0.3 & $3.5 \times 10^{6}$ \\
\hline & & $q \quad Q$ & 7 & $10^{-8}$ & 7 & $10^{-8}$ & 7 & $10^{-8}$ \\
\hline \multirow{6}{*}{30} & \multirow{3}{*}{5} & $M \quad I_{\max }$ & 35 & 3500 & 35 & 3500 & 35 & 3500 \\
\hline & & $\alpha_{1} \quad \alpha_{2}$ & 0.3 & $3.5 \times 10^{6}$ & 0.3 & $3.5 \times 10^{6}$ & 0.3 & $3.5 \times 10^{6}$ \\
\hline & & $q \quad Q$ & 7 & $10^{-8}$ & 7 & $10^{-8}$ & 7 & $10^{-8}$ \\
\hline & \multirow{3}{*}{10} & $M \quad I_{\max }$ & 45 & 3500 & 45 & 3500 & 45 & 3500 \\
\hline & & $\alpha_{1} \quad \alpha_{2}$ & 0.3 & $3.5 \times 10^{6}$ & 0.3 & $3.5 \times 10^{6}$ & 0.3 & $3.5 \times 10^{6}$ \\
\hline & & $q$ & 7 & $10^{-8}$ & 7 & $10^{-8}$ & 7 & $10^{-8}$ \\
\hline
\end{tabular}

Table 5.2: Parameter settings for data set 2 . 


\subsection{Experimental Results}

All the settings for the proposed heuristics were implemented four times for each problem instance, and the best solution was reported. Tables 5.3 and 5.4 summarize the results obtained for data set 1 and data set 2, respectively, for each heuristic. For data set 1 , the results are compared with the results obtained by using the TS heuristic (Kaku and Mazzola, 1997), SA heuristic (Kuppusamy, 2001), cutting planes (CP) algorithm (Lacksonen and Enscore, 1993), and Urban's pairwise exchange heuristic solutions (UB) presented by Kaku and Mazzola (1997). For data set 2, the results are compared with the results from the GA presented by Balakrishnan and Cheng (2000) and the results from the SA heuristic presented by Baykasouglu and Gindy (2001).

In the tables, the bold numbers, before the 'ACO Best' column, gives the best solutions found by one of the ACO heuristics. If the best solution found by using ACO heuristic is worse than the solution previously found, the latter is bold and the best solution only within ACO is italic.

For data set 1 , most of the best solutions could be obtained by using the TS and CP heuristics. For the 32 test problems, TS found the best solution for 27 problems (i.e., did not find the best for only problems 19, 20, 21, 27 and 31). However, the CP heuristic found the best solution for only 20 problems. The SA heuristic found the best solution 18 times. For the ACO heuristics (ACO I, ACO II and ACO III), the best-found solution was found for 19 problems (59.4\%). The numbers of solutions obtained within $1 \%$ and within $1-2 \%$ of the best-found solutions are $11(34.3 \%)$ and 2 
(6.3\%), respectively. The $\mathrm{CP}$ and $\mathrm{ACO}$ heuristics performed pretty much the same. However, for this data set, the TS heuristic performs better than all of the heuristics.

The ACO I, II, and III heuristics obtained the same solutions for 18 of the 32 test problems in data set 1 . For the remaining 13 test problems, the ACO I heuristic produced the best solution for only 1 of the test problems (test problem 21). The ACO II heuristic found the best solutions for 9 of the remaining test problems, and ACO III obtained the best solution for 4 of the remaining test problems. Therefore, ACO II out-performed ACO I and III for data set 1. See table 5.5 for computational times for data set 1 ACO heuristics. 


\begin{tabular}{|c|c|c|c|c|c|c|c|c|c|c|c|c|}
\hline \multicolumn{2}{|c|}{ Problem Size (data set1) } & \multirow[b]{2}{*}{ P No } & \multirow[b]{2}{*}{ ACOI } & \multirow[b]{2}{*}{ ACO II } & \multirow[b]{2}{*}{ ACO III } & \multirow{2}{*}{$\begin{array}{l}\text { ACO } \\
\text { Best }\end{array}$} & \multirow[b]{2}{*}{ SA } & \multirow[b]{2}{*}{ UB } & \multirow[b]{2}{*}{$\mathbf{C P}$} & \multirow[b]{2}{*}{ TS } & \multirow[b]{2}{*}{ Best Found } & \multirow{2}{*}{$\begin{array}{l}\% \text { within best } \\
\text { found solution }\end{array}$} \\
\hline $\begin{array}{l}\text { No. of } \\
\text { departments }\end{array}$ & $\begin{array}{l}\text { No. of } \\
\text { time period }\end{array}$ & & & & & & & & & & & \\
\hline \multirow{8}{*}{6} & \multirow{4}{*}{3} & P01 & 267 & 267 & 267 & 267 & 267 & 291 & 267 & 267 & 267 & 0 \\
\hline & & P02 & 260 & 260 & 260 & 260 & 260 & 281 & 260 & 260 & 260 & 0 \\
\hline & & $\mathrm{P} 03$ & 363 & 363 & 363 & 363 & 363 & 385 & 363 & 363 & 363 & 0 \\
\hline & & P04 & 299 & 299 & 299 & 299 & 299 & 312 & 299 & 299 & 299 & 0 \\
\hline & \multirow{4}{*}{5} & P05 & 442 & 442 & 442 & 442 & 442 & 472 & 442 & 442 & 442 & 0 \\
\hline & & P06 & 596 & 596 & 596 & 596 & 596 & 617 & 589 & 586 & 586 & 1.706 \\
\hline & & P07 & 424 & 424 & 424 & 424 & 424 & 500 & 424 & 424 & 424 & 0 \\
\hline & & P08 & 428 & 428 & 428 & 428 & 428 & 452 & 428 & 428 & 428 & 0 \\
\hline \multirow{8}{*}{12} & \multirow{4}{*}{3} & P09 & 1624 & 1624 & 1624 & 1624 & 1624 & 1676 & 1624 & 1624 & 1624 & 0 \\
\hline & & P10 & 1973 & 1973 & 1973 & 1973 & 1973 & 2000 & 1973 & 1973 & 1973 & 0 \\
\hline & & P11 & 1661 & 1661 & 1661 & 1661 & 1661 & 1779 & 1661 & 1661 & 1661 & 0 \\
\hline & & P12 & 2105 & 2105 & 2105 & 2105 & 2105 & 2298 & 2097 & 2097 & 2097 & 0.381 \\
\hline & \multirow{4}{*}{5} & P13 & 2966 & 2976 & 2955 & 2955 & 2966 & 3050 & 2930 & 2930 & 2930 & 0.853 \\
\hline & & P14 & 3725 & 3725 & 3712 & 3712 & 3715 & 3886 & 3726 & 3701 & 3701 & 0.297 \\
\hline & & P15 & 2756 & 2756 & 2756 & 2756 & 2756 & 3125 & 2756 & 2756 & 2756 & 0 \\
\hline & & P16 & 3364 & 3364 & 3364 & 3364 & 3364 & 3730 & 3364 & 3364 & 3364 & 0 \\
\hline \multirow{9}{*}{20} & \multirow{4}{*}{3} & P17 & 2758 & 2758 & 2758 & 2758 & 2758 & 2925 & 2763 & 2758 & 2758 & 0 \\
\hline & & P18 & 5318 & 5318 & 5318 & 5318 & 5318 & 5363 & 5318 & 5318 & 5318 & 0 \\
\hline & & P19 & 3080 & 3064 & 3100 & 3064 & 3064 & 3924 & 3048 & 3056 & 3048 & 0.525 \\
\hline & & P20 & 5965 & 5949 & 5968 & 5949 & 5947 & 7147 & 5873 & 5903 & 5873 & 1.294 \\
\hline & \multirow{4}{*}{5} & P21 & 4615 & 4677 & 4660 & 4615 & 4663 & 4964 & 4581 & 4605 & 4581 & 0.742 \\
\hline & & P22 & 9963 & 9837 & 9845 & 9837 & 9897 & 10530 & 9825 & 9746 & 9746 & 0.934 \\
\hline & & P23 & 4654 & 4654 & 4654 & 4654 & 4654 & 6512 & 4654 & 4654 & 4654 & 0 \\
\hline & & P24 & 8989 & 8979 & 8985 & 8979 & 8979 & 10816 & 8985 & 8979 & 8979 & 0 \\
\hline & & P25 & 7154 & 7351 & 7130 & 7130 & 7131 & 7516 & 7163 & 7130 & 7130 & 0 \\
\hline
\end{tabular}




\begin{tabular}{|c|c|c|c|c|c|c|c|c|c|c|c|c|}
\hline \multirow{7}{*}{30} & \multirow{3}{*}{3} & $\mathrm{P} 26$ & 14481 & 14528 & 14478 & 14478 & 14519 & 14729 & 14583 & 14478 & 14478 & 0 \\
\hline & & P27 & 8141 & 8093 & 8103 & 8093 & 8093 & 10465 & 8066 & 8115 & 8066 & 0.335 \\
\hline & & $\mathrm{P} 28$ & 15033 & 15025 & 15080 & 15025 & 15074 & 15285 & 14940 & 14925 & 14925 & 0.670 \\
\hline & \multirow{4}{*}{5} & $\mathrm{P} 29$ & 14255 & 13647 & 13719 & 13647 & 13753 & 14103 & 13719 & 13606 & 13606 & 0.301 \\
\hline & & P30 & 25828 & 25787 & 25825 & 25787 & 25721 & 26223 & 26027 & 25583 & 25583 & 0.797 \\
\hline & & P31 & 12264 & 12242 & 12320 & 12242 & 12148 & 15738 & 12351 & 12163 & 12148 & 0.649 \\
\hline & & P32 & 24300 & 24200 & 24200 & 24200 & 24200 & 27680 & 24409 & 24200 & 24200 & 0 \\
\hline
\end{tabular}

Table 5.3: Solution results for data set 1 . 


\begin{tabular}{|c|c|c|c|c|c|c|c|c|c|c|c|}
\hline \multicolumn{2}{|c|}{ Problem Size (data set 2 ) } & \multirow[b]{2}{*}{ No. } & \multirow[b]{2}{*}{ ACO I } & \multirow[b]{2}{*}{ ACO II } & \multirow[b]{2}{*}{ ACO III } & \multirow[b]{2}{*}{$\begin{array}{c}\text { ACO } \\
\text { Best }\end{array}$} & \multirow[b]{2}{*}{$\mathbf{S A}$} & \multirow[b]{2}{*}{ NLGA } & \multirow[b]{2}{*}{ CONGA } & \multirow[b]{2}{*}{$\begin{array}{c}\text { Best } \\
\text { Found }\end{array}$} & \multirow{2}{*}{$\begin{array}{c}\text { \% within } \\
\text { best found } \\
\text { solution }\end{array}$} \\
\hline $\begin{array}{l}\text { No. of } \\
\text { department }\end{array}$ & $\begin{array}{l}\text { No. of } \\
\text { time period }\end{array}$ & & & & & & & & & & \\
\hline \multirow{16}{*}{6} & \multirow{8}{*}{5} & $\mathrm{P} 01$ & 106419 & 106419 & 106419 & 106419 & 107249 & 106419 & 108976 & 106419 & 0 \\
\hline & & P02 & 104834 & 104834 & 104834 & 104834 & 105710 & 104834 & 105170 & 104834 & 0 \\
\hline & & P03 & 104320 & 104320 & 104320 & 104320 & 104800 & 104320 & 104520 & 104320 & 0 \\
\hline & & P04 & 106399 & 106399 & 106399 & 106399 & 106515 & 106515 & 106719 & 106515 & -0.1091 \\
\hline & & P05 & 105737 & 105628 & 105628 & 105628 & 106282 & 105628 & 105628 & 105628 & 0 \\
\hline & & P06 & 103985 & 103985 & 103985 & 103985 & 103985 & 104053 & 105605 & 103985 & 0 \\
\hline & & P07 & 106439 & 106439 & 106439 & 106439 & 106447 & 106978 & 106439 & 106439 & 0 \\
\hline & & P08 & 103771 & 103771 & 103771 & 103771 & 103771 & 103771 & 104485 & 103771 & 0 \\
\hline & \multirow{8}{*}{10} & P09 & 214313 & 214313 & 214313 & 214313 & 215200 & 214397 & 218407 & 214397 & -0.0392 \\
\hline & & $\mathrm{P} 10$ & 212134 & 212134 & 212134 & 212134 & 214713 & 212138 & 215623 & 212138 & -0.0019 \\
\hline & & P11 & 208060 & 207987 & 207987 & 207987 & 208351 & 208453 & 211028 & 208351 & -0.1747 \\
\hline & & P12 & 212530 & 212530 & 212741 & 212530 & 213331 & 212953 & 217493 & 212953 & -0.1986 \\
\hline & & $\mathrm{P} 13$ & 210906 & 210906 & 210906 & 210906 & 213812 & 211575 & 215363 & 211575 & -0.3162 \\
\hline & & P14 & 209962 & 209932 & 209932 & 209932 & 211213 & 210801 & 215564 & 210801 & -0.4122 \\
\hline & & $\mathrm{P} 15$ & 214252 & 214252 & 214252 & 214252 & 215630 & 215685 & 220529 & 215630 & -0.6391 \\
\hline & & P16 & 213767 & 212588 & 212719 & 212588 & 214513 & 214657 & 216291 & 214513 & -0.8974 \\
\hline \multirow[b]{9}{*}{15} & \multirow{8}{*}{5} & P17 & 481511 & 481395 & 481697 & 481395 & 484695 & 511854 & 504759 & 484695 & -0.6808 \\
\hline & & P18 & 485594 & 484761 & 484879 & 484761 & 486141 & 507694 & 514718 & 486141 & -0.2839 \\
\hline & & P19 & 490899 & 488748 & 490398 & 488748 & 496617 & 518461 & 516063 & 496617 & -1.5845 \\
\hline & & $\mathrm{P} 20$ & 485561 & 485658 & 485995 & 485561 & 490869 & 514242 & 508532 & 490869 & -1.0813 \\
\hline & & $\mathrm{P} 21$ & 489012 & 488364 & 489206 & 488364 & 491501 & 512834 & 515599 & 491501 & -0.6382 \\
\hline & & $\mathrm{P} 22$ & 488954 & 486685 & 486965 & 486685 & 491098 & 513763 & 509384 & 491098 & -0.8986 \\
\hline & & $\mathrm{P} 23$ & 487315 & 486853 & 487315 & 486853 & 491350 & 512722 & 512508 & 491350 & -0.9152 \\
\hline & & $\mathrm{P} 24$ & 493963 & 492074 & 491466 & 491466 & 496465 & 521116 & 514839 & 496465 & -1.0069 \\
\hline & & $\mathrm{P} 25$ & 982208 & 980351 & 982112 & 980351 & 950910 & 1047596 & 1055539 & 950910 & 3.0960 \\
\hline
\end{tabular}




\begin{tabular}{|c|c|c|c|c|c|c|c|c|c|c|c|}
\hline & \multirow{7}{*}{10} & $\mathrm{P} 26$ & 981802 & 980680 & 980662 & 980662 & 947673 & 1037580 & 1061940 & 947673 & 3.4810 \\
\hline & & $\mathrm{P} 27$ & 978027 & 986039 & 984065 & 978027 & 968027 & 1056185 & 1073603 & 968027 & 1.0330 \\
\hline & & $\mathrm{P} 28$ & 978987 & 977708 & 975854 & 975854 & 950701 & 1026789 & 1060034 & 950701 & 2.6457 \\
\hline & & P29 & 980611 & 980548 & 980134 & 980134 & 948470 & 1033591 & 1064692 & 948470 & 3.3384 \\
\hline & & $\mathrm{P} 30$ & 973690 & 971827 & 971548 & 971548 & 948630 & 1028606 & 1066370 & 948630 & 2.4159 \\
\hline & & P31 & 985659 & 982708 & 980752 & 980752 & 965844 & 1043823 & 1066617 & 965844 & 1.5435 \\
\hline & & P32 & 987986 & 987430 & 985707 & 985707 & 956170 & 1048853 & 1068216 & 956170 & 3.0890 \\
\hline \multirow{16}{*}{30} & \multirow{8}{*}{5} & P33 & 579414 & 579503 & 580240 & 579414 & 562405 & 611794 & 632737 & 562405 & 3.0243 \\
\hline & & P34 & 572204 & 571528 & 574531 & 571528 & 569251 & 611873 & 647585 & 569251 & 0.4000 \\
\hline & & P35 & 578152 & 576053 & 578150 & 576053 & 564464 & 611664 & 642295 & 564464 & 2.0531 \\
\hline & & P36 & 569694 & 572005 & 570924 & 569694 & 552684 & 611766 & 634626 & 552684 & 3.0777 \\
\hline & & P37 & 558353 & 558353 & 558353 & 558353 & 559596 & 604564 & 639693 & 559596 & -0.2221 \\
\hline & & P38 & 569725 & 570567 & 572811 & 569725 & 592515 & 606010 & 637620 & 592515 & -3.8463 \\
\hline & & P39 & 570899 & 572484 & 570691 & 570691 & 582409 & 607134 & 640482 & 582409 & -2.0120 \\
\hline & & $\mathrm{P} 40$ & 576396 & 575998 & 576280 & 575998 & 578549 & 620183 & 635776 & 578549 & -0.4409 \\
\hline & \multirow{8}{*}{10} & P41 & 1172034 & 1179688 & 1181500 & 1172034 & 1122154 & 1228411 & 1362513 & 1122154 & 4.4450 \\
\hline & & $\mathrm{P} 42$ & 1203538 & 1177398 & 1176513 & 1176513 & 1120182 & 1231987 & 1379640 & 1120182 & 5.0287 \\
\hline & & P43 & 1164078 & 1125204 & 1140320 & 1125204 & 1125346 & 1231829 & 1365024 & 1125346 & -0.0126 \\
\hline & & $\mathrm{P} 44$ & 1190140 & 1160501 & 1159514 & 1159514 & 1120217 & 1227413 & 1367130 & 1120217 & 3.5080 \\
\hline & & $\mathrm{P} 45$ & 1128855 & 1142776 & 1142776 & 1128855 & 1158323 & 1215256 & 1356860 & 1158323 & -2.5440 \\
\hline & & $\mathrm{P} 46$ & 1153982 & 1111344 & 1139040 & 1111344 & 1111344 & 1221356 & 1372513 & 1111344 & 0 \\
\hline & & $\mathrm{P} 47$ & 1122805 & 1121735 & 1155220 & 1121735 & 1128744 & 1212273 & 1382799 & 1128744 & -0.6210 \\
\hline & & $\mathrm{P} 48$ & 1136157 & 1136157 & 1180450 & 1136157 & 1136157 & 1245423 & 1383610 & 1136157 & 0 \\
\hline
\end{tabular}

Table 5.4: Solution results for data set 2 . 
For data set 2, the ACO heuristics found the best solutions for 33 of the 48 test problems (test problems $1-24,37-40,43,45-48$ ). For 24 of the test problems, (50\%), the ACO heuristics obtained better solutions than the best solutions obtained using the other heuristics. The best-found solutions were obtained for 9 (18.8\%) test problems. The numbers of solutions obtained within $1 \%, 1-2 \%, 2-3 \%, 3-4 \%, 4-5 \%$, and $5-6 \%$ of the best-found solutions are $1(2.1 \%), 2(4.2 \%), 3(6.3 \%), 7(14.6 \%), 1$ $(2.1 \%)$, and $1(2.1 \%)$, respectively. For test problems 1 to 24 , all the solutions obtained by the ACO heuristics are better than or equal to the other heuristics. For test problems 25 to problem 48, SA produced the best solution for 15 of the test problems, and the ACO heuristics found the best solution for 9 of the test problems. Hence, the ACO heuristics out-performed the other heuristics for small-size problems. However, the SA heuristic performs slightly better than the ACO heuristics for large size problems. ACO II out-performed ACO I and III for data set 2. See table 5.6 for computational time for data set 2 ACO heuristics. 


\begin{tabular}{|c|c|c|c|c|c|}
\hline \multicolumn{2}{|c|}{ Problem Size } & \multirow[b]{2}{*}{ P No } & \multirow[b]{2}{*}{ ACO I } & \multirow[b]{2}{*}{ ACO II } & \multirow[b]{2}{*}{ ACO III } \\
\hline Size & Time Period & & & & \\
\hline \multirow{8}{*}{6} & \multirow{4}{*}{3} & $\mathrm{P} 01$ & 0.170 & 0.175 & 0.172 \\
\hline & & $\mathrm{P} 02$ & 0.160 & 0.165 & 0.160 \\
\hline & & $\mathrm{P} 03$ & 0.190 & 0.200 & 0.191 \\
\hline & & P04 & 0.192 & 0.200 & 0.192 \\
\hline & \multirow{4}{*}{5} & $\mathrm{P} 05$ & 0.220 & 0.242 & 0.234 \\
\hline & & $\mathrm{P} 06$ & 0.189 & 0.197 & 0.188 \\
\hline & & P07 & 0.200 & 0.227 & 0.212 \\
\hline & & P08 & 0.186 & 0.196 & 0.190 \\
\hline \multirow{8}{*}{12} & \multirow{4}{*}{3} & P09 & 0.320 & 0.420 & 0.355 \\
\hline & & P10 & 0.370 & 0.437 & 0.380 \\
\hline & & P11 & 0.289 & 0.411 & 0.300 \\
\hline & & P12 & 0.315 & 0.401 & 0.343 \\
\hline & \multirow{4}{*}{5} & P13 & 0.530 & 0.749 & 0.540 \\
\hline & & P14 & 0.510 & 0.712 & 0.547 \\
\hline & & $\mathrm{P} 15$ & 0.521 & 0.732 & 0.549 \\
\hline & & P16 & 0.503 & 0.688 & 0.502 \\
\hline \multirow{8}{*}{20} & \multirow{4}{*}{3} & P17 & 3.120 & 4.083 & 3.390 \\
\hline & & P18 & 3.230 & 4.883 & 3.433 \\
\hline & & P19 & 3.108 & 4.233 & 3.283 \\
\hline & & $\mathrm{P} 20$ & 3.149 & 4.440 & 3.343 \\
\hline & \multirow{4}{*}{5} & $\mathrm{P} 21$ & 5.150 & 7.417 & 6.010 \\
\hline & & $\mathrm{P} 22$ & 5.130 & 7.417 & 5.956 \\
\hline & & $\mathrm{P} 23$ & 5.410 & 7.435 & 6.240 \\
\hline & & P24 & 4.982 & 7.028 & 6.000 \\
\hline \multirow{8}{*}{30} & \multirow{4}{*}{3} & $\mathrm{P} 25$ & 10.417 & 14.980 & 11.020 \\
\hline & & P26 & 11.027 & 14.820 & 11.689 \\
\hline & & P27 & 10.538 & 14.270 & 11.233 \\
\hline & & P28 & 10.467 & 14.599 & 11.433 \\
\hline & \multirow{4}{*}{5} & P29 & 17.285 & 24.375 & 19.289 \\
\hline & & P30 & 17.460 & 24.500 & 19.463 \\
\hline & & P31 & 17.189 & 23.876 & 18.673 \\
\hline & & P32 & 18.060 & 24.673 & 20.050 \\
\hline
\end{tabular}

Table 5.5: Computational times for data set 1 (times are given in minutes). 


\begin{tabular}{|c|c|c|c|c|c|}
\hline \multicolumn{2}{|c|}{ Problem Size } & \multirow[b]{2}{*}{ P No } & \multirow[b]{2}{*}{ ACO I } & \multirow[b]{2}{*}{ ACO II } & \multirow[b]{2}{*}{ ACO III } \\
\hline Size & Time Period & & & & \\
\hline \multirow{16}{*}{6} & \multirow{8}{*}{5} & $\mathrm{P} 01$ & 0.187 & 0.282 & 0.280 \\
\hline & & $\mathrm{P} 02$ & 0.167 & 0.280 & 0.280 \\
\hline & & $\mathrm{P} 03$ & 0.186 & 0.299 & 0.282 \\
\hline & & P04 & 0.180 & 0.285 & 0.260 \\
\hline & & P05 & 0.176 & 0.260 & 0.255 \\
\hline & & P06 & 0.185 & 0.279 & 0.278 \\
\hline & & P07 & 0.184 & 0.270 & 0.266 \\
\hline & & P08 & 0.179 & 0.265 & 0.265 \\
\hline & \multirow{8}{*}{10} & P09 & 1.400 & 1.410 & 1.410 \\
\hline & & P10 & 1.411 & 1.411 & 1.407 \\
\hline & & P11 & 1.406 & 1.407 & 1.406 \\
\hline & & P12 & 1.406 & 1.407 & 1.406 \\
\hline & & $\mathrm{P} 13$ & 1.401 & 1.407 & 1.405 \\
\hline & & P14 & 1.421 & 1.420 & 1.420 \\
\hline & & P15 & 1.440 & 1.441 & 1.440 \\
\hline & & P16 & 1.410 & 1.420 & 1411 \\
\hline \multirow{23}{*}{15} & \multirow{8}{*}{5} & P17 & 3.122 & 3.250 & 3.122 \\
\hline & & P18 & 3.125 & 3.255 & 3.155 \\
\hline & & P19 & 3.140 & 3.320 & 3.148 \\
\hline & & $\mathrm{P} 20$ & 3.140 & 3.330 & 3.140 \\
\hline & & $\mathrm{P} 21$ & 3.141 & 3.320 & 3.161 \\
\hline & & $\mathrm{P} 22$ & 3.145 & 3.324 & 3.189 \\
\hline & & $\mathrm{P} 23$ & 3.120 & 3.420 & 3.170 \\
\hline & & P24 & 3.128 & 3.440 & 3.174 \\
\hline & \multirow{8}{*}{10} & $\mathrm{P} 25$ & 9.580 & 11.120 & 10.500 \\
\hline & & P26 & 9.650 & 12.120 & 10.890 \\
\hline & & P27 & 9.780 & 11.359 & 10.700 \\
\hline & & $\mathrm{P} 28$ & 9.290 & 11.489 & 10.600 \\
\hline & & P29 & 9.440 & 12.020 & 11.014 \\
\hline & & P30 & 10.120 & 12.040 & 11.140 \\
\hline & & P31 & 10.220 & 12.142 & 11.248 \\
\hline & & P32 & 9.990 & 11.780 & 10.560 \\
\hline & \multirow{7}{*}{5} & P33 & 15.250 & 17.250 & 16.230 \\
\hline & & P34 & 15.350 & 17.000 & 16.480 \\
\hline & & P35 & 14.780 & 16.250 & 16.116 \\
\hline & & P36 & 15.230 & 17.120 & 17.012 \\
\hline & & P37 & 14.480 & 16.480 & 15.786 \\
\hline & & P38 & 14.387 & 17.010 & 16.016 \\
\hline & & P39 & 14.460 & 16.569 & 15.688 \\
\hline
\end{tabular}




\begin{tabular}{|c|c|c|c|c|c|}
\hline \multirow{9}{*}{30} & & P40 & 14.623 & 17.000 & 16.342 \\
\hline & \multirow{8}{*}{10} & P41 & 32.540 & 41.120 & 32.150 \\
\hline & & P42 & 32.670 & 40.080 & 32.260 \\
\hline & & P43 & 31.256 & 39.170 & 31.540 \\
\hline & & P44 & 31.670 & 40.147 & 32.265 \\
\hline & & P45 & 32.060 & 39.622 & 33.065 \\
\hline & & $\mathrm{P} 46$ & 34.020 & 42.120 & 36.017 \\
\hline & & P47 & 33.226 & 41.246 & 36.268 \\
\hline & & P48 & 31.250 & 40.100 & 38.120 \\
\hline
\end{tabular}

Table 5.6: Computational time for data set 2 (times are given in minutes). 


\section{CHAPTER 6}

\section{CONCLUSION}

\subsection{Summary of Research}

This research develops heuristics utilizing the ACO heuristic for the QAP (HAS-QAP) to obtain good solutions for the DFLP. Because the ACO heuristic was never used to solve the DFLP, the HAS-QAP heuristic was modified to consider rearrangement cost and to efficiently solve the DFLP. Three ACO heuristics (ACO I, ACO II and ACO III) were proposed to solve the DFLP. The ACO I heuristic is a direct modification of the HAS-QAP heuristic to solve the DFLP. The ACO II heuristic is similar to the ACO I heuristic but with a look-ahead and look-back mechanism, and ACO III combines a SA heuristic with the ACO I heuristic.

The proposed heuristics were tested on two data sets with 80 test problem instances taken from the literature, and the results were presented. The proposed heuristics obtained the best-found solutions for 26 problem instances and obtained the best solutions ever published for 24 problem instances. Moreover, the solutions for 14 problem instances were within $1 \%$ of the best-found solutions. From these results, it is concluded that the ACO heuristics are very good heuristics for solving the DFLP. Furthermore, good solutions can be obtained in reasonable time.

\subsection{Recommendations for Future Research}

The following recommendations may be considered for future research: 
1. Use another method for calculating rearrangement costs since these costs are not usually fixed in real-world problems (e.g., cost can depend on time periods and/or travel distances for moving machines and equipment).

2. Consider the DFLP with unequal size departments.

3. Consider stochastic flow data for the DFLP.

4. Combine other existing heuristics (e.g., TS and ACO) to obtain better solutions for the DFLP.

5. Consider both the block layout and the detailed layout (i.e., layout of the machines within the departments), simultaneously, for the DFLP. 


\section{REFERENCES}

Armour, G.C. and Buffa, E.S., 1963, "A heuristic algorithm and simulation approach to relative location of facilities," Management Science, Vol. 9, pp. 294-309.

Balakrishnan, J., 1993, “Note:'The Dynamics of Plant Layout',” Management Science, Vol. 39, No.5, May.

Balakrishnan, J. and Cheng, C.H., 2000, "Genetic search and the dynamic layout problem," Computers and Operations Research, Vol. 27, pp. 587-593.

Balakrishnan, J., Cheng, C.H., and Conway, G., 2000, "An improved pair-wise exchange heuristic for the dynamic plant layout problem," International Journal of Production Research, Vol. 38, No.13, pp. 3067-3077.

Balakrishnan, J., Jacobs, F.R., and Venkataramanan, M.A., 1992, "Solutions for the constrained dynamic facility layout problem," European Journal of Operational Research, Vol. 57, pp. 280-286.

Baykosoglu, A. and Gindy, N.N.Z., 2001, "A simulated annealing algorithm for dynamic facility layout problem," Computers and Operations Research, Vol. 28, pp. 1403-1426.

Bazaraa, M.S., 1975, "Computerized layout design: A branch and bound approach," IIE Transaction, Vol. 7, pp. 432-437.

Bland, J.A., 1999, "Layout of facilities using an ant system approach", Journal of Engineering optimization, Vol. 32, pp. 101-115.

Bozer, Y.A., Meller, R.D., and Erlebacher, S.J., 1994, “An Improvement-type Layout Algorithm for Single and Multiple-floor Facilities," Management Science, Vol. 40, No. 7, pp. 918-932.

Bozer, Y.A. and Meller, R.D., 1997, "A reexamination of the distance-based facility layout problem," IIE Transaction, Vol. 29, No. 7, pp. 549-560.

Burkard, R.E. and Bonniger, T., 1983, "A heuristic for quadratic Boolean problems with application to quadratic assignment problem," European Journal of Operations Research, Vol. 13, pp. 374-386.

Burkard, R.E. and Cela, E., 1998, "Heuristic for biquadratic assignment problems and their computational comparison," European Journal of Operational Research, Vol. 83, 
No. 2, pp. 283-300.

Burkard, R.E., Cela, E., Rote, G., and Woeqinger, G.J., 1997, "Quadratic assignment problem with a monotone anti-monge and a symmetric toeplitz matrix: Easy and hard cases," Proceedings of the 1996 5th International IPCO Conference, Vol. 1084, pp. 204-209.

Burkard, R.E. and Rendl, F., 1984, "A Thermodynamically motivated Simulation Procedure for Combinatorial Optimization Problems," European Journal of Operational Research, Vol. 17, pp. 169-174.

Burkard, R.E. and Stratman, K.H., 1978, "Numerical investigations on Quadratic Assignment Problems," Naval Research Logistics Quarterly, Vol. 25, pp. 129-144.

Chiang, W.C. and Chiang, C., 1998, "Intelligent local search strategies for solving facility layout problems with the quadratic assignment problem formulation," European Journal of Operational Research, Vol. 106, pp. 457-488.

Chiang and P. Kouvelis, 1996, "An improved Tabu Search heuristic for solving facility layout design problems," International Journal of Production Research, Vol.34, No.9, pp. 2565-2585.

Conway, D.G. and Venkataramanan, M.A., 1994, "Genetic Search and the Dynamic Facility Layout Problem," Computer \& Operations Research, Vol. 21, No. 8, pp. 955-960.

Dorigo, M., 1992, "Optimization, Learning and Natural Algorithms," Ph.D.Thesis, Italy, in Italian.

Dorigo, M., G. Di Caro \& L. M. Gambardella ,1999, “Ant Algorithms for Discrete Optimization,” Artificial Life, Vol. 5, No. 2, pp. 137-172.

Dorigo, M. and Gambardella, L.M., 1997a, "Ant Colony System: A Cooperative Learning Approach to the Traveling Salesman Problem," IEEE Transactions on Evolutionary Computation, Vol. 1, No. 1, pp. 53-66.

Dorigo, M. and Gambardella, L.M., 1997b, "Ant Colonies for the Traveling Salesman Problem,” BioSystems, Vol. 43, pp. 73-81.

Dorigo, M., Maniezzo, V., and Colorni, A., 1996, "The Ant System: Optimization by a Colony of Cooperating Agents," IEEE Transactions on Systems, Man, and Cybernetics-Part B, Vol. 26, No. 1, pp. 29-41.

El-Rayah, T.E. and Hollier, R.H., 1970, "Review of plant design techniques," 
International Journal of Production Research, Vol. 8, No. 3, pp. 263-79.

Foulds, L.R. and Robinson, D.F., 1976, "A strategy for solving the plant layout problem,"Operations Research, Vol. 27, No. 4, pp. 845-855.

Francis, R.L., McGinnis Jr., L.F., and White, J.A., 1992,"Facility Layout and Location: An Analytical Approach,” Englewood Cliffs, NJ: Prentice-Hall.

Francis, R.L. and White, J.A., 1974,"Facility Layout and Location: An Analytical Approach,” Englewood Cliffs, NJ: Prentice-Hall.

Gambardella, L.M., Taillard, E.D., and Dorigo, M., 1999, "Ant Colonies for the Quadratic Assignment Problem," Journal of Operational Research Society, Vol. 50, pp. 167-176.

Gilmore, P.C., 1962, "Optimal and Suboptimal Algorithms for the Quadratic Assignment Problem," Journal of the Society for the Industrial and Applied Mathematics, Vol. 10, pp. 305-313.

Glover, F., 1989, “Tabu Search- Part I,” ORSA Journal on Computing, Vol. 1, No. 3, pp. 190-206.

Glover, F., 1990, “Tabu Search- Part II,” ORSA Journal on Computing, Vol. 2, No. 1, pp. 4-32.

Gomory, R.E., and Hu, T.C., 1961, "Multi-terminal network flows," SIAM Journal, Vol. 9, pp.551-570.

Heragu, S.S., 1991, "Efficient models for the facility layout problem," European Journal of Operational Research, Vol. 53, No. 1, pp. 1-13.

Heragu, S.S., 1992, "Recent models and techniques for solving the layout problem," European Journal of Operational Research, Vol. 57, No. 2, pp. 136-144.

Hitchings, G.G., 1970, "Control, redundancy, and change in layout systems," AIIE Transaction, Vol. 2, No. 3, pp. 253-262.

Kaku, B.K. and Mazzola, J.B., 1997, "A Tabu search Heuristic for the Dynamic Plant Layout Problem," Informs Journal on Computing, Vol. 9, No. 4, pp. 374-384.

Kaku, B.K. and Thompson,G.L., 1986, "An exact algorithm for the general quadratic assignment problem," European Journal of Operational Research, Vol. 23, pp. 382-390. 
Kochhar, J.S. and Heragu, S.S, 1999, "Facility layout design in a changing environment," International Journal of Production Research, Vol. 37, No. 11, pp. 2429-2446.

Koopmans, T.C. and Beckman, M.J., 1957, “Assignment problems and the location of economic activities," Econometrical, Vol. 25, pp. 53-76.

Kuppusamy, S. 2001, "Simulated annealing heuristics for the dynamic facility layout problem", Master Thesis, West Virginia University.

Lacksonen, T.A., 1997, "Preprocessing for Static and Dynamic Facility Layout Problem," International Journal of Production Research, Vol. 35, No. 4, pp. 1095-1106.

Lacksonen, T.A. and Enscore, E.E., 1993, "Quadratic Assignment Algorithms for the Dynamic Layout Problem," International Journal of Production Research, Vol. 31, No. 3, pp. 503-517.

Maniezzo V., Colorni, A. and M. Dorigo, 1994, "The Ant System Applied to the Quadratic Assignment Problem," Tech. Rep.

Maniezzo V. and Colorni, A., 1999, "The Ant System Applied to the Quadratic Assignment Problem," IEEE Transactions on Knowledge and Data Engineering, to appear.

Meller, R.D. and Gau, K.Y., 1996a, "The Facility layout problem: Recent and Emerging Trends and Perspectives," Journal of Manufacturing Systems, Vol. 15, No. 5, pp. 351-366.

Meller, R.D. and Gau, K.Y., 1996b, "Facility layout objective functions and Robust Layouts," International Journal of Production Research, Vol. 34, No. 10, pp. 2727-2742.

Rockwell, T.H., and Wilhelm, W.E., 1990, "Material flow management in cellular configurations for small-lot, circuit card assembly," International Journal of Production Research, Vol. 28, No.3, pp. 573-593.

Rosenblatt, M.J., 1986, “The dynamics of plant layout," Management Science, Vol. 32, No. 1, pp. 76-86.

Pardalos, P.H. and Crouse, J.V., 1989, “A parallel algorithm for the QAP,” Proceeding of the 1989 Supercomputer Conference, pp. 351-360.

Shore, R.H., and Tompkins, J.A., 1980, "Flexible facilities design,” AIIE Transaction, 
Vol. 12, No. 2, pp. 200-205.

Skorin-Kopov, J., 1990, "Tabu Search Applied to the Quadratic Assignment Problem," Operations Research Society of America Journal on Computing, Vol. 2, No.1

Skorin-Kopov, J., 1994, "Extensions of a Tabu Search Adaptation to the Quadratic Assignment Problem," Computer Operations Research, Vol.21, No.8, pp. 855-865

Souilah, A., 1995, "Simulated Annealing for the Manufacturing Systems Layout Design,” European Journal Of Operational Research, Vol. 82, pp. 592-614.

Sule, D.R., 1988, “Manufacturing Facility Location Planning and Design,” Boston, PWS-Kent, pp. 294-355.

Tate, D.E. and Smith, A.E., 1995a, "A Genetic Approach to the Quadratic Assignment Problem," Computers and Operations Research, Vol. 22, pp.73-83.

Tompkins, J.A. and Reed, R., 1976, "An applied model for the facilities design problem," International Journal of Production Research, Vol. 14, No. 5, pp. 583-595.

Tompkins, J.A., White, J.A., Bozer, Y.A., Frazelle, E.H., Tanchoco, J.M.A., and Trevino, J., 1996, “Facilities Planning,” New York, John Wiley \& Sons, Inc.

Urban, T.L., 1987, "A Multiple Criteria Model for the Facilities Layout Problem," International Journal of Production Research, Vol. 25, No.12, pp. 1805-1812.

Urban, T.L., 1993, "A heuristic for the dynamic facility layout problem," IIE Transactions, Vol. 25, No. 4, pp. 57-63.

Urban, T.L., 1998, "Solution Procedures for the Dynamic Facility Layout Problem", Annals of Operations Research, Vol. 76, pp. 323-342.

Yaman, R., Gethin, D.T., and Clarke, M.J., 1993, "Effective sorting method for facility layout construction," International Journal of Production Research, Vol. 31, No. 2, pp. 413-427. 